\title{
石墨烯/碳纳米管复合材料的制备及应用进展
}

\author{
赵冬梅 ${ }^{*, a, b}$ 李振伟 ${ }^{c}$ 刘领弟 ${ }^{c} \quad$ 张艳红 $^{c} \quad$ 任德财 ${ }^{b}$ 李坚*, $a$ \\ ( ${ }^{a}$ 东北林业大学生物材料科学与工程教育部重点实验室＼cjkstart哈尔滨１50040) \\ ( ${ }^{b}$ 黑龙江东方学院食品与环境工程学部 哈尔滨 150086) \\ ( 黑龙江大学功能无机材料化学教育部重点实验室 哈尔滨 150080)
}

\begin{abstract}
摘要 石墨烯和碳纳米管都是纳米尺寸的碳材料, 具有极大的比表面积、良好的导电性以及优秀的机械性能等特性. 选择合适的方法制备出石墨烯/碳纳米管复合材料, 它们之间可以产生一种协同效应，使其各种物理化学性能得到增 强, 因而这种复合材料在很多领域有着极大的应用前景. 以石墨烯/碳纳米管复合材料为综述对象, 详细地介绍了它的 制备、掺杂和应用等方面的进展, 同时也对其发展前景进行了展望. 这种复合材料不仅被成功地应用在电容器、光电 器件、储能电池、电化学传感器和其它领域, 而且也会在这些领域内深化并向其它领域延伸.
\end{abstract}

关键词 石墨烯; 碳纳米管; 复合材料; 制备; 应用

\section{Progress of Preparation and Application of Graphene/Carbon Nanotube Composite Materials}

\author{
Zhao, Dongmei*,a,b \\ Li, Zhenweic ${ }^{c}$ \\ Ren, Decai ${ }^{b}$ \\ Liu, Lingdic \\ $\mathrm{Li}, \mathrm{Jian}^{*, a}$ \\ Zhang, Yanhong ${ }^{c}$
}

$\left({ }^{a}\right.$ Key Laboratory of Bio-Based Material Science and Technology, Ministry of Education, Northeast Forest University, Harbin 150040)

$\left({ }^{b}\right.$ Food and Environment Engineering Department, Heilongjiang East University, Harbin 150086)

( ${ }^{c}$ Key Laboratory of Functional Inorganic Material Chemistry, Heilongjiang University, Harbin 150080)

\begin{abstract}
Graphene and carbon nanotubes are nanometer-sized carbon materials with the characteristics of the great specific surface area, good electrical conductivity and excellent mechanical properties. Selecting appropriate methods to prepare graphene/carbon nanotube composites can generate a synergistic effect between them with many physical and chemical properties enhanced, and these composites have a great future in many areas. In this paper, some kinds of preparation methods about graphene/carbon nanotube composites were described in detail, such as chemical vapor deposition, layer by layer deposition, electrophoretic deposition, vacuum filtration, coating membrane and in situ chemical reduction method. The advantages and disadvantages of these methods were compared as table format. To further enhance the functions, the graphene/carbon nanotube composites were doped with other materials such as polymer materials, nanoparticles, metal oxide to achieve the purpose of modification. Some researchers proposed theoretical computer model design for some special composites structures such as three-dimensional columnar structure and spiral structure to improve the performance of composites. Meanwhile, the applications of composites in supercapacitor, a photoelectric conversion device, energy storage batteries, electrochemical sensors and other fields were discussed in detail. These applications fully proved that composites had a brighter future than pure graphene or carbon nanotube. In addition, the developments of composites are prospected. Preparations of grapheme/carbon nanotube composites are maturing, but a variety of methods have their drawbacks and shortcomings, to get preparation method with easy control operation, low production costs, high raw material utilization, good product quality needs further research and exploration. Preparations of the highly oriented columnar structures between the layers of graphene and carbon nanotube and three-dimensional structure with graphene helicaly inserted or wrapped carbon nanotubes still remain in the computer model. In the near future the studies of the composites will be deepen and extended to develop new fields.
\end{abstract}

Keywords graphene; carbon nanotube; composite; preparation; application

\section{1 引言}

碳纳米管(CNT)和石墨烯(Graphene)分别在 1991 年
和 2004 年被人们所发现, 而且从它们被发现的那天起 就一直备受瞩目. 碳纳米管是一种具有特殊结构的一维 量子材料, 它的径向尺寸可达到纳米级, 轴向尺寸为微

* E-mail: zhaodongmei0322@yahoo.com.cn; Tel.: 0451-86653157

Received August 15, 2013; published November 3, 2013.

Project supported by the National Natural Science Foundation of China (No. 31270590), Postdoctoral Science Foundation Projects of China (No. 2013M531008) and Heilongjiang Provincial Department of Education Project (No. 12531521).

项目受国家自然科学基金(No. 31270590)、中国博士后基金(No. 2013M531008)和黑龙江省教育厅项目(No. 12531521)资助. 
米级，管的两端一般都封口，因此它有很大的强度，同 时巨大的长径比有望使其制作成韧性极好的碳纤维. 石 墨烯是一种由碳原子以 $\mathrm{sp}^{2}$ 杂化轨道组成的六角型呈蜂 巢晶格的平面薄膜, 只有一个碳原子厚度的二维碳材 料. 零维富勒烯、一维碳纳米管、二维石墨烯共同组成 了骨干的碳纳米材料家族, 并且它们之间可以在形式上 转化 ${ }^{[1]}$ (见图 1).

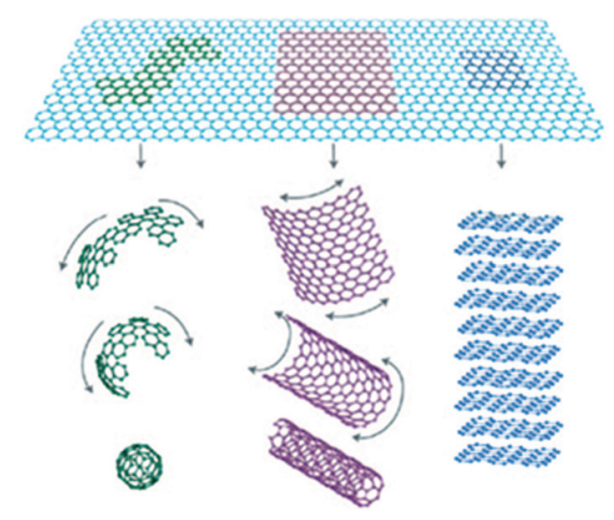

图 1 石墨烯: 各种石墨形体之母 ${ }^{[1]}$

Figure 1 Graphene: the parent of all graphitic forms ${ }^{[1]}$

石墨烯和碳纳米管在电学和力学等方面有着相似 的性质，但由于结构不同，它们也有很多不同之处. 碳 纳米管和石墨烯分别是优良的一维和二维碳材料, 它们 分别体现出了一维的和二维的各向异性, 如导电性、力 学性能和导热性等. 为了结合两者的优点, 人们将石墨 烯和碳纳米管共同用于复合材料 ${ }^{[2,3]}$. 石墨烯和碳纳米 管复合材料形成三维网状结构, 通过它们之间的协同效 应, 使其表现出比任意一种单一材料更加优异的性能, 例如更好的各向同性导热性 ${ }^{[4]}$ 、各向同性导电性 ${ }^{[5]}$ 、三 维空间微孔网络 ${ }^{[6 \sim 8]}$ 等特性. 基于以上性质, 使得石墨 烯/碳纳米管复合材料在超级电容器、太阳能电池、显示 器、生物检测、燃料电池等方面有着良好的应用前景. 此 外, 掺杂一些改性剂的石墨烯/碳纳米管复合材料也受 到人们的广泛关注, 例如在石墨烯/碳纳米管复合电极 上添加 $\mathrm{CdTe}$ 量子点制作光电开关 ${ }^{[9]}$ 、掺杂金属颗粒制 作场致发射装置 ${ }^{[10]}$. 由此可见, 石墨烯/碳纳米管复合 材料越来越多的被人们所应用, 也使得石墨烯/碳纳米 管复合材料的制备和应用得到更加广泛的关注. 本文综 述了石墨烯/碳纳米管复合材料的制备方法、掺杂改性及 应用方面的成果，也对其广阔的发展前景进行了展望.

\section{2 石墨烯/碳纳米管复合材料的制备方法}

\section{1 化学气相沉积法(CVD)}

CVD 法因易于控制膜的组成及成份分散度而被广 泛应用于制备石墨烯/碳纳米管复合膜. 根据沉积机理 不同, CVD 法分为常规 CVD 法、等离子体增强 CVD 法 (PECVD)等.

\subsection{1 常规 CVD 法}

利用 CVD 法 ${ }^{[7,11 ~ 19]}$ 制备石墨烯/碳纳米管复合薄膜 的一般步骤是：首先利用 CVD 法在铜䈃等基底沉积上 一层石墨烯薄膜, 然后在石墨烯薄膜上涂上一层催化剂 (一般为金属颗粒), 接着再次利用 CVD 法在催化剂表面 沉积一层碳纳米管, 最后用化学腐蚀法去除铜箔等基 底，这样就得到了石墨烯/碳纳米管复合薄膜. Choi 等 ${ }^{[11]}$ 首先在 $\mathrm{SiO}_{2} / \mathrm{Si}$ 基底上镀一层 $100 \mathrm{~nm}$ 的镍膜, 然后通入 混合气体 $\mathrm{Ar} / \mathrm{H}_{2}$ 并对其进行 $900{ }^{\circ} \mathrm{C}$ 的热处理，随后，保 持温度和气流不变的情况下向反应室内通入 $\mathrm{C}_{2} \mathrm{H}_{2}$, 等 石墨烯薄膜在基底上长好以后，逐渐冷却(约 100 ${ }^{\circ} \mathrm{C} \cdot \mathrm{min}^{-1}$ ) 基底，再把长有石墨烯的基底放入 $1 \mathrm{~mol} / \mathrm{L}$ $\mathrm{FeCl}_{3}$ 溶液中除去镍. 随后 $6 \mathrm{~nm}$ 厚的铁膜沉积在石墨烯 层上, 然后在 $\mathrm{Ar} / \mathrm{NH}_{3}$ 混合气流下和在 $900{ }^{\circ} \mathrm{C}$ 下进行热 处理. 改变催化剂和混合气体的流量, 用相同的方法利 用范德华力在石墨烯薄膜上沉积多壁碳纳米管，最后把 制备的复合薄膜转移到导电玻璃上制成电极. 这种在石 墨烯层表面垂直生长的碳纳米管可以增大电解质/对电 极的界面表面积，使得石墨烯/碳纳米管复合电极有更 好的化学性质, 从而在太阳能电池中的应用中有更加优 异的性能. $\mathrm{Li}$ 等 ${ }^{[12]}$ 利用还原的氧化石墨烯 (RGO) 和 $\mathrm{Fe}_{3} \mathrm{O}_{4}$ 带有相反电荷的特点而制成混合胶体作为催化剂 前驱体, 取 $10 \mathrm{mg}$ 放入石英容器内, 通入氩气和氢气, 以 $10{ }^{\circ} \mathrm{C} / \mathrm{min}$ 的速度升温至 $600{ }^{\circ} \mathrm{C}$ 维持 $150 \mathrm{~min}, \mathrm{Fe}_{3} \mathrm{O}_{4}$ 纳米粒子被还原成 $\mathrm{Fe}$ 纳米粒子. 在该温度下通入 $\mathrm{C}_{2} \mathrm{H}_{2}$ 和 $\mathrm{NH}_{3}$ 并反应 $30 \mathrm{~min}$ 后改通 $\mathrm{Ar}$ 和 $\mathrm{H}_{2}$ 直到温度降为室 温. 用此方法得到的氮掺杂碳纳米管呈卷曲状, 并且发 现生长碳纳米管的密度与掺杂 $\mathrm{Fe}_{3} \mathrm{O}_{4}$ 纳米粒子的密度呈 正比关系, 只有当 $\mathrm{Fe}_{3} \mathrm{O}_{4} / \mathrm{RGO}$ 混合胶体中 $\mathrm{Fe}_{3} \mathrm{O}_{4}$ 的密度 达到一定程度后, 得到的氮掺杂碳纳米管才呈现出高度 规整的矩阵. 具有良好电导率的石墨烯和氮掺杂碳纳米 管的复合材料在电极中将有望代替贵重金属. Hong 等 ${ }^{[13]}$ 首先使用 CVD 法制备单纯石墨烯、碳纳米管薄膜, 然后采用转印法制备复合薄膜. Nguyen 等 ${ }^{[14]}$ 采用一种 快速升温和冷却的 CVD 法制备出不同厚度的石墨烯/碳 纳米管复合薄膜, 石墨烯层作为有效的电池障碍物可以 阻止来自铁纳米粒子的中毒从而保证碳纳米管可以在 铜基体上生长, 通过研究它的导电性和场发射性发现此 复合薄膜在光电、能源和传感器装置方面有着良好的应 用前景. 与常规 CVD 法相比, 这种方法降低了能耗、减 少了反应时间，有助于大规模、低成本的制备石墨烯/ 碳纳米管复合薄膜.

Chen 等 ${ }^{[15]}$ 采用一种原位化学气相还原沉积法 (CVRD)直接用氧化石墨烯 $(\mathrm{GO})$ 制备石墨烯/碳纳米管 复合材料. 其制备步骤为(图 2): 首先制备 $\mathrm{GO} / \mathrm{Co}(\mathrm{OH})_{2}$ 复合纳米粒子，然后将复合纳米粒子放入管式炉里，通 入混合气体 $\left(\mathrm{C}_{2} \mathrm{H}_{2}: 5 \%, \mathrm{~N}_{2}: 95 \%, 80 \mathrm{sccm}\right)$. 再升温至 500 ${ }^{\circ} \mathrm{C}$, 分别进行 $2 \mathrm{~min} 、 5 \mathrm{~min} 、 1 \mathrm{~h}$ 的化学气相还原沉积反 
应，结束后使反应炉在纯氮气的保护下缓慢冷却至室 温, 把所得到的产品在 $0.6 \mathrm{~mol} \cdot \mathrm{L}^{-1} \mathrm{HCl}$ 溶液中浸泡 $10 \mathrm{~h}$ 以除去 Co 催化剂, 然后离心、水洗、干燥后即得到石 墨烯/碳纳米管复合材料. 由于反应时间不同, 石墨烯上 生长的碳纳米管长度也不相同. 通过对比发现, 碳纳米 管最短的复合材料的电化学性能最佳, 以该材料为电极 制作成的锂电池的电容量也是最大的.

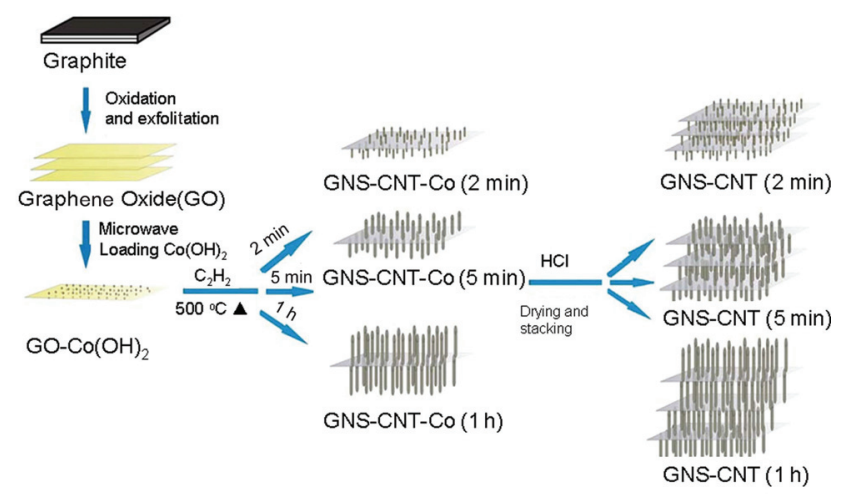

图 2 多层石墨烯/碳纳米管纳米复合材料的合成过程示意图 ${ }^{[15]}$, GNS: graphene nanosheet

Figure 2 Schematic illustration of the synthetic process of multilayered graphene/CNT nanocomposites ${ }^{[15]}$, GNS is the abbreviation of graphene nanosheet

最近，有报道使用一步 CVD 法制备石墨烯/碳纳米 管复合材料, 即只使用一次 CVD 法而使石墨烯和碳纳 米管同时沉积在基底上. 该方法减少了反应步骤, 缩短 了反应时间, 降低了生产成本, 有利于大规模生产这种 复合材料. Dong 等 ${ }^{[18]}$ 以乙醇作为前驱体, 通过简单的一 步化学气相沉积法合成了石墨烯/碳纳米管复合材料: 使用 $\mathrm{Si}$ 纳米颗粒修饰的铜䈃作为基体, 石墨烯在基体 上均匀生长, 碳纳米管以硅纳米粒子为起点生长形成网 状结构. 经研究发现, 碳纳米管的密度可以通过 CVD 的生长温度来控制. 电性质研究表明, 以此种方法制备 的石墨烯/碳纳米管呈现出优异的场效应性能, 与 CVD 法生长的纯石墨烯相比电导率得到极大的提高. Zhu 等 ${ }^{[19]}$ 使用 $\mathrm{MgO}$ 和 $\mathrm{Fe} / \mathrm{MgO}$ 的混合物作为催化剂, 使用 一步 CVD 法制备了带有磁性的石墨烯/碳纳米管复合材 料.

利用常规 CVD 法可以制备出非常均匀的薄膜, 而 且薄膜的成分易于控制, 重复性好, 在超大规模集成电 路中很多薄膜大都采用 CVD 法制备. 此外, 经典的 CVD 技术可以不受基体表面形状的限制很容易的得到 均匀生长的 CNT 薄膜, 而且还可以使 CNT 在石墨烯基 体表面垂直生长, 形成大面积的碳纳米管森林. 但是, CVD 技术操作起来需要大于 $800{ }^{\circ} \mathrm{C}$ 的高温, 而有些器 件在高温环境下不稳定, 从而限制了常规 CVD 法在有 些材料制备上的应用.

\subsection{2 等离子体增强 CVD (PECVD)}

PECVD 法是在常规 CVD 法 ${ }^{[10,20 ~ 22]}$ 的基础上所形
成的一种制备薄膜的方法，其原理为：借助微波或射频 等使含有薄膜组成原子的气体电离, 在局部形成等离子 体，而等离子化学活性很强，很容易发生反应，在基片 上沉积出所期望的薄膜. Lee 等 ${ }^{[20]}$ 先制备以 $\mathrm{SiO}_{2} / \mathrm{Si}$ 为基 体的氧化石墨烯薄膜, 然后在薄膜上自组装纳米多孔嵌 段共聚物模板，再在模板上沉积铁离子膜. 超声去掉嵌 段共聚物模板, 从而铁离子催化剂保留在氧化性薄膜 上. 在 $600{ }^{\circ} \mathrm{C}$ 、压力为 $666.6 \mathrm{~Pa}$ 的环境下, 通以 $\mathrm{C}_{2} \mathrm{H}_{2} / \mathrm{H}_{2} /$ $\mathrm{NH}_{3}$ 气流，并在 $470 \mathrm{~V}$ 的直流电压下产生等离子体，在 氧化石墨烯薄膜上垂直生长出碳纳米管. 由于处理温度 高, 氧化石墨烯被还原为石墨烯从而保证了导电性. 用 化学腐蚀法把硅基底去除即得到高导电性的石墨烯/碳 纳米管复合薄膜. $\mathrm{Yu}$ 等 ${ }^{[21]}$ 在常压环境下, 利用 PECVD 法制备出一种寡层石墨烯(FLG)/碳纳米管 3D 复合材料, 其结构和树枝与树叶的关系相似, 石墨烯片层以化学键 的方式与碳纳米管结合, 图 3 有效的证明了这一点. 这 种接合方式与简单的混合相比，大大提高了复合材料的 导电性和传感效应.

和常规 CVD 法相比, PECVD 法可以在较低的温度 下进行化学气相沉积, 而且其沉积速度快, 成膜质量好, 不易龟裂. 但它也有一定的缺点, 比如成本大, 对气体 的纯度要求高, 且在反应过程中会产生剧烈噪音、强光 辐射、有害气体等影响.

\section{2 逐层沉积法 $(\mathrm{LBL})$}

逐层沉积 $(\mathrm{LBL})$ 法是利用逐层交替沉积的原理，通 过溶液中目标化合物与基片表面功能基团的弱相互作 用(如静电引力、氢键等)或强相互作用(如化学键等)驱 使目标化合物自发地在基板上缔合形成结构完整、性能 稳定、具有某种特殊功能薄膜的一门技术. 其中最常见 的组装驱动力是静电引力, 即基于表面带有相反电荷的 不同化合物间的交替吸附，实现正负电荷的过度补偿， 从而得到具有特定厚度的薄膜.

自从 1991 年 Decher 首次提出通过静电引力层层组 装形成薄膜的方法后，该技术在制膜领域中得到广泛应 用. 目前，使用 LBL 法制备石墨烯/碳纳米管复合薄膜 的驱动力大都是静电引力 ${ }^{[8,23 ~ 28]}$. Hong 等 ${ }^{[23]}$ 使用 LBL 法 成功的在硅基表面制备出多层石墨烯/碳纳米管复合薄 膜，经过热处理复合膜的电导率得到极大的提高. 而且 该复合薄膜具有很好的光电性能，在电子传送、储能、 传感器等方面都有着广泛的应用前景. $\mathrm{Yu}$ 等 ${ }^{[8]}$ 在使用肼 还原氧化石墨烯时加入一定量的聚亚胺(PEI)作为稳定 剂，从而制备了稳定分散在水中的 PEI 修饰的石墨烯. PEI 不仅能使石墨烯稳定地分散在水溶液中, 而且还可 以为石墨烯提供阳离子 $\left(\mathrm{NH}_{4}^{+}\right)$. 他们使用 PEI 修饰的石 墨烯与带有羧基的多壁碳纳米管逐层组装成多层的复 合薄膜. 这些复合膜具有内部交联的网络碳结构并带有 纳米孔, 循环伏安法表征发现在 $1 \mathrm{~V} / \mathrm{s}$ 的扫描速度下单 位电容可达到 $120 \mathrm{~F} / \mathrm{g}$, 在超级电容器方面有很好的应 

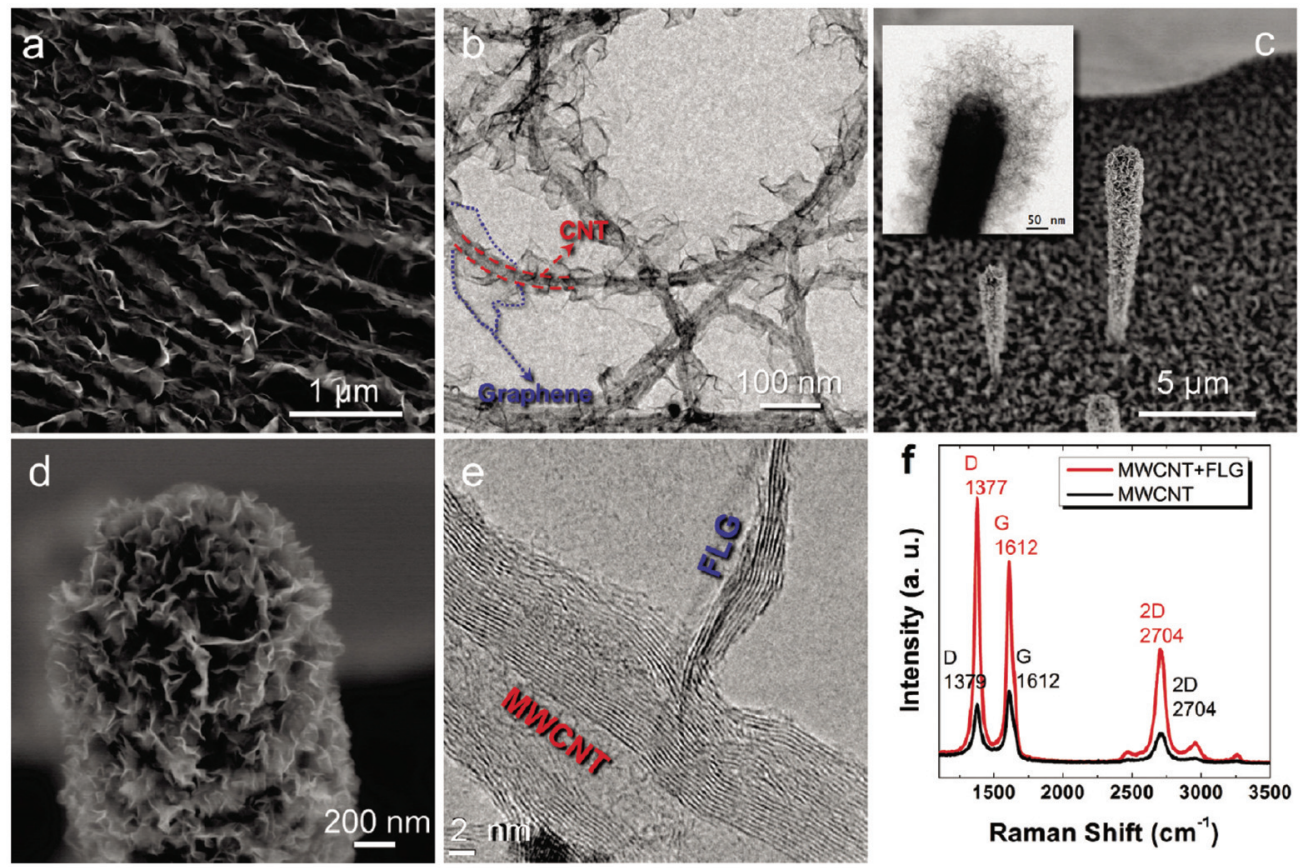

图 3 (a) CNT-FLG 杂化结构的 SEM 照片, (b)悬在微栅上长有寡层石墨烯的碳纳米管的 TEM 照片, (c)长在垂直碳纳米管上的寡层石墨烯的 SEM 照片，插入的是一幅 TEM 照片, (d)图 c 中 CNT-FLG 近照, (e) CNT-FLG 结构的高分辨率 TEM 照片, (f) 原 CNT 膜(黑线)和 CNT-FLG 膜(红线)的 Raman 光谱 ${ }^{[21]}$

Figure 3 (a) SEM image of CNT-FLG hybrid structures. (b) TEM image of FLGs grown on CNTs suspended on a Cu TEM grid. (c) SEM image of FLGs grown on vertically aligned CNTs; the inset is a TEM image of the tip of a CNT-FLG. (d) A close view of the CNT-FLG tip in panel c. (e) HRTEM image of a CNT-FLG structure. (f) Raman spectra of pristine CNT (black) and CNT-FLG (red) films ${ }^{[21]}$

用前景. Byon 等 ${ }^{[24]}$ 认为使用绝缘的高聚物(例如 PEI)修 饰石墨烯会导致电极的电学性能降低. 他们用 Hummers 法制备出的氧化石墨烯和胺功能化的碳纳米管在不同 基底上逐层沉积出多层复合薄膜, 然后在 $120{ }^{\circ} \mathrm{C}$ 的肼蒸 汽下还原成石墨烯/碳纳米管复合薄膜. 由于电极表面 的氧化还原反应，用该复合薄膜制作的电极在酸性电解 液中有着更大的单位电容.

以上实验都是在平面基底上逐层沉积出复合薄膜, 而在曲面上同样可以利用 LBL 法制备石墨烯/碳纳米管 复合薄膜. Hong 等 ${ }^{[25]}$ 通过 LBL 法用带正电的多壁碳纳 米管和带负电的还原氧化石墨烯在硅胶粒子表面逐层 沉积出多层石墨烯/碳纳米管复合薄膜, 然后使之浸泡 在含有氟硅烷的正己烷溶液中 $20 \mathrm{~min}$ 进行氟化, 制备出 具有超疏水性的胶体粒子, 而且可以通过改变复合薄膜 的层数来改变胶体粒子的表面粗粘度来改变胶体粒子 与水的接触角 $\left(119^{\circ} \sim 151^{\circ}\right)$, 制备出表面疏水性能不同 的胶体粒子. 考虑到石墨烯和碳纳米管的广泛应用, 这 种方法很可能在制备多功能复合薄膜方面开启一个新 的领域.

LBL 法的突出的优点在于只需改变电解溶液的离 子强度和调节溶液的 $\mathrm{pH}$ 值, 就能改变组装膜内吸附分 子的链结构和组装膜的表面结构, 从而实现对组装膜的 厚度、组分、密度的有效调控. 但与 CVD 法相比, 尽管 LBL 法制备石墨烯/碳纳米管复合薄膜具有方法简单、
成本低、应用范围广等诸多优点，但该方法使用的石墨 烯和碳纳米管一般带有活性官能团, 例如䍭基、氨基等. 当用作电化学器件时, 在电流的催化下, 这些游离的官 能团易发生不可逆的氧化还原反应, 将会严重影响器件 的整体性能，最终极大的缩短其使用寿命，因此，增加 石墨烯/碳纳米管的电化学稳定性是其走应用的关键.

\section{3 电泳沉积法}

电泳沉积法 ${ }^{[28 ~ 34]}$ 是一种既经济而又应用广泛的沉 积技术，其基本原理为：在胶体溶液中对电极施加电压 时，带电胶体粒子移向电极表面放电而形成沉积层. 由 于其潜在的技术应用，在所有的沉积方式中，电泳沉积 被认为是其中最吸引人的一个. 现在, 电泳沉积法已经 被广泛用在导电基片上沉积薄膜，而且用该方法制作的 薄膜有很多突出的优点, 例如沉积速率高、均质性好、 膜厚易控且不需添加粘接剂等. 近年来, 使用电泳沉积 法制备碳材料薄膜，也逐渐得到人们的重视，例如，Wu 等 ${ }^{[29]}$ 使用电泳沉积法制备出单层石墨烯并研究它的场 致发射特性. 因此，电泳沉积法也开始被用来制备石墨 烯/碳纳米管复合薄膜.

在使用电泳沉积制备石墨烯/碳纳米管复合薄膜的 过程中, 其关键步骤就是配制分散均匀的石 墨烯/碳纳 米管稳定悬浮液, 而且悬浮液中的胶体粒子必须带有电 荷，这样才能使粒子在外加电场的作用下向电极移动， 并形成沉积薄膜. 为了形成带电的胶体粒子, 其中一种 
常用的方法就是先用无机酸或碱对石墨烯和碳纳米管 进行处理，从而使它们带上活性官能团，例如羧基和氨 基等. Bon 等 ${ }^{[30]}$ 使用带有羧基的碳纳米管和带有残氧基 的石墨烯直接混合分散到 $1 \mathrm{mg} / \mathrm{mL}$ 的 $N$-甲基吡咯烷䤊 (NMP)中, 超声 $1 \mathrm{~h}$ 得到黑色悬浮液, 然后静置一个月. 电泳沉积时, 在涂有聚对苯二甲酸乙二醇酯(PET) 的 ITO 电极上施加 $1 \mathrm{~V}$ 或 $5 \mathrm{~V}$ 的电压, 金电极上不施加电 压, 所以带有电负性的石墨烯移向 ITO 电极放电而形成 沉积层. 当他们单独使用石墨烯进行电泳沉积时, 发现 石墨烯形成一种聚集结构, 只有加入碳纳米管时才能沉 积出连续的碳材料薄膜. 另一种使胶体粒子带上电荷的 办法就是向稳定分散的石墨烯/碳纳米管悬浮液中添加 金属盐, 胶体粒子吸附金属阳离子形成带电粒子, 而且 沉积后的薄膜在电极上具有很强的粘附力. $\mathrm{Lu}$ 等 ${ }^{[31]}$ 使用 丙酮和乙醇 $(1: 1, V: V)$ 的混合液制备不同比例的石墨 烯/碳纳米管分散液. 超声分散 $24 \mathrm{~h}$ 以形成稳定的悬浮 液, 然后加入一定量的 $\mathrm{Al}\left(\mathrm{NO}_{3}\right)_{3} \cdot 9 \mathrm{H}_{2} \mathrm{O}$ 用以加快沉积速 率和增加粒子与基底的粘接力度. 复合膜中的碳纳米管 作为 “导电线” 将片层还原氧化石墨烯连接起来, 使得 其具有很好的电容性. 将不同比例组成的复合膜进行对 比, 发现当复合物中碳纳米管的质量分数为 $40 \%$ 时它们 的协同效应最好，在此比例之下，二维石墨烯和一维碳 纳米管形成了良好的三维网络结构, 碳纳米管作为导 线, 链接了石墨烯片层, 提高了电解质离子传输的效率, 放电时间最长，电容量为 $87 \mathrm{~F} / \mathrm{g}$. Seo 等 ${ }^{[32]}$ 先将多壁碳纳 米管进行酸化, 在电场的作用下使得石墨烯/碳纳米管 的异丙醇悬浮液沉积到 $\mathrm{Ni}$ 电极上形成复合膜. 其中往 混合悬浮液中加入硝酸镍, 为石墨烯和碳纳米管提供 $\mathrm{Ni}^{+}$, 有利于混合物分散和电泳沉积. 这种电泳沉积所 得的直接组装使得石墨烯/碳纳米管有效地组合而没有 发生聚集, 有利于得到高电化学性能的复合电极, 从而 更好地应用于锂离子电池. 最近, Ata 等 ${ }^{[33]}$ 使用一种新 的有机溶剂金黄色素三甲酸来制备石墨烯/碳纳米管复 合薄膜, 为石墨烯和碳纳米管提供负电荷从而在阳极表 面进行沉积, 且使得其很好地分散. 他们还发现, 使用 金黄色素三甲酸制备石墨烯/碳纳米管复合材料，不仅 避免了因官能团的引入对碳纳米管结构的破坏, 而且还 避免了因使用金属盐而引入杂质, 因而他们也为电泳沉 积法制备石墨烯/碳纳米管复合薄膜开辟了一条新道路.

\section{4 真空抽滤法}

与以上几种方法相比, 真空抽滤法是一种更为简单 的成膜技术, 在制备高性能导电薄膜等方面具有广泛的 应用前景. 近年来, 在制备碳材料薄膜方面, 已有人利 用真空抽滤法制备出高透明导电性的石 墨烯薄膜 ${ }^{[35]}$ 和

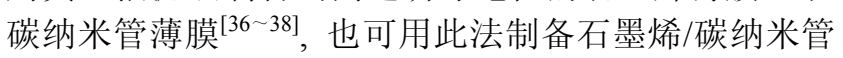
复合膜. 利用真空抽滤法制备石墨烯/碳纳米管复合薄 膜的首要步骤是配置出分散稳定的悬浮液, 然后使用薄 膜(例如聚四氟乙烯薄膜、聚碳酸酯薄膜)真空过滤, 最
后通过薄膜与基底间的相互作用转移该薄膜到基底上. 目前，主要有三种方法用来配置石墨烯/碳纳米管混合 溶液: (1)使用 NMP 等有机溶剂 ${ }^{[39,40]}$ : 一些有机溶剂(例 如 NMP)可以分散和剥离碳纳米管 ${ }^{[41 ~ 44]}$; 在类似 NMP 的有机溶剂中可对石墨进行剥离并得到无缺陷的石墨 烯 ${ }^{[45]}$, 而且得到的石墨烯产量很大并且没有表面化学修 饰. 基于以上, 可以用 NMP 溶剂将石墨烯和碳纳米管 进行分散得到复合分散液，为真空过滤法制备复合薄膜 提供了可能. (2)以水为溶剂并添加少量表面活性剂: 石 墨烯和碳纳米管在水中不能很好地分散，但当加入少量 表面活性剂后，由于亲水性官能团的作用，也可配制成 分散良好的分散液. Tang 等 ${ }^{[46]}$ 将表面活性剂聚苯乙烯磺 酸钠加入石墨烯的水分散液中, 高剪切速率下进行分 散, 将表面活性剂 Triton-X100 加入到碳纳米管水分散 液中, 将两者混合制得分散均匀的石墨烯/碳纳米管悬 浮液, 并用亲水性聚碳酸酯薄膜高压过滤, 制得石墨烯/ 碳纳米管薄膜, $120{ }^{\circ} \mathrm{C}$ 处理去除水和表面活性剂. King 等 ${ }^{[47]}$ 使用胆酸钠作为表面活性剂和稳定剂制得石墨烯/ 碳纳米管均匀悬浮液, 真空抽滤后得到石墨烯/碳纳米 管复合膜，少量石墨烯的加入可以提高导电性且对透明 性没有影响, 其中 $3 \mathrm{wt} \%$ 石墨烯掺杂的复合膜的导电性 提高了 $40 \%$. (3)以水为溶剂, 先分散氧化石墨烯, 然后 再还原成石墨烯：由于氧化石墨烯带有亲水性的官能 团，所以可以均匀地分散在水中，而且其类似于苯环的 结构可以与碳纳米管的侧壁相连接, 在亲水性的含氧官 能团的作用下，使得氧化石墨烯/碳纳米管复合物均匀 地分散在水溶液中 ${ }^{[48 ~ 50]}$. $\mathrm{Lu}$ 等 ${ }^{[51]}$ 首先利用真空过滤法 制备出氧化石墨烯/碳纳米管复合薄膜，然后向反应室 内通入肼蒸汽使氧化石墨烯还原成石墨烯, 制得石墨 烯/碳纳米管复合薄膜并表征了其优良的电化学性能.

真空抽滤法制备的薄膜厚度可以通过配置不同浓 度和体积的悬浮液得到精确的控制, 此外, 它还具有操 作简单、成膜均匀以及原料利用率高等优点，适合实验 室条件下的基础科学研究. 但是抽滤成膜的面积受滤纸 面积的限制, 而且在石墨烯/碳纳米管的抽滤过程中, 由 于石墨烯片层的层层叠加, 使得抽滤速度越来越慢直至 停止，从而限制大厚度薄膜的制备.

\section{5 涂制成膜法}

与抽滤成膜相似，涂制成膜也是一种简单的成膜技 术. 涂制成膜一般要首先配置分散均匀的石墨烯/碳纳 米管复合分散液, 然后选用不同的仪器, 在目标基底上 涂制成膜，根据成膜的仪器不同，涂制成膜还可分为喷 涂法 ${ }^{[52,53]}$ 和旋涂法 ${ }^{[54]}$.

上文提到过, 氧化石墨烯由于带有亲水性的含氧官 能团而与石墨烯很好地分散在水中, 从而得到稳定的氧 化石墨烯/碳纳米管悬浮液. Dong 等 ${ }^{[52]}$ 首先采用喷涂法 制备出氧化石墨烯/碳纳米管复合薄膜，然后利用肼蒸 汽在 $80{ }^{\circ} \mathrm{C}$ 下还原成石墨烯/碳纳米管复合薄膜, 此复合 
膜具有明显的核壳结构, 这种核壳结构的形成是两种材 料之间强烈的 $\pi-\pi$ 堆积作用力. 这种混合材料在电发光 和超级电容器方面有很大的应用前景. Jang 等 ${ }^{[53]}$ 使用一 种带有双喷嘴的喷雾机, 采用高压空气为载气, 成功地 在玻璃基底上喷制出一层非共价键连接的氧化石墨烯/ 碳纳米管复合薄膜. 为了提高该复合薄膜的电导率, 他 们并没有使用传统的肼还原氧化石墨烯技术(他们认为 该方法需要在高温下进行而限制了柔性基底的使用), 而是把该薄膜进行了两次硝酸处理从而增大了氮原子 密度, 增大了石墨烯片层与碳纳米管之间的载流子密 度, 从而极大地提高了该复合薄膜的电导率. Kim 等 ${ }^{[54]}$ 利用喷涂法也成功地在 ITO 电极上制得一层石墨烯/碳 纳米管复合薄膜并将其应用在高聚物太阳能电池中. 与 传统的阳极修饰剂(PEDOT:PSS)相比, 石墨烯/碳纳米 管复合材料的相关性能也毫不逊色, 并且在某些方面还 优于 PEDOT:PSS, 例如石墨烯/碳纳米管复合薄膜(几纳 米)的厚度比 PEDOT:PSS(一般为 $40 \mathrm{~nm}$ )要小很多、在 长波长段中具有很高的光传输性等.

相对于抽滤成膜技术, 涂制成膜制得薄膜的面积由 祄底的尺寸进行控制, 厚度也可以通过改变仪器的参数 进行调节, 制膜工艺简单高效. 但是该方法制得的薄膜 厚度不均匀, 而且原料的利用率也相对较低.

\section{6 原位化学还原法}

原位化学还原法是一门传统的制备纳米复合材料 的技术. 利用该方法可以简单、直接地制备出石墨烯/ 碳纳米管粉体, 其步骤大都是先用 Hummer 法制备出氧 化石墨烯, 然后与碳纳米管混合分散在溶剂中, 选用一 种合适的还原剂进行原位还原, 最终制得石墨烯/碳纳 米管复合材料. Yang 等 ${ }^{[55]}$ 选用乙二醇作为还原剂, 并在 冰水浴下加到已经稳定分散的不同比例的氧化石墨烯/ 碳纳米管复合水溶液中, 超声分散均匀, 使用 PTFE 膜 进行过滤然后烘干即制得分级结构的石墨烯 (graphenes: GNS)/碳纳米管复合碳材料, 该材料显示出
极高的电容性, 极高的能量和电流密度, 其制备过程如 图 4 所示.

Woo 等 ${ }^{[56]}$ 首先使用 Hummer 法制备出氧化石墨烯, 对多壁碳纳米管进行酸化处理，将石墨烯与碳纳米管混 合分散在水中，用肼溶液和氨水进行还原. 对还原后的 产物进行过滤和烘干得到混合粉末，然后用玻璃碳电极 制备石墨烯/碳纳米管复合电极并用红外线灯干燥，此 改性的复合膜电极在电化学传感器方面有很好的应用 前景. 最近 $\mathrm{Hu}$ 等 ${ }^{[57]}$ 采用聚醚酰亚胺(PEI)作为还原剂制 备石墨烯/碳纳米管复合材料, PEI 是一种优秀的成膜物 质, 得到的复合材料呈现出优异的成膜性能从而提高了 修饰电极的稳定性. 将多壁碳纳米管和还原氧化石墨烯 复合，电极表面呈现多孔结构，所以该电极制作的传感 器可以同时检测间苯二酚、对苯二酚、对甲酚和亚硝酸 盐，因而石墨烯/碳纳米管复合材料有望在环境污染检 测方面得到很好的应用.

\section{7 其它制备方法}

除了以上几种常用方法外，还有很多方法被用来制 备石墨烯/碳纳米管复合材料，还有一些创新性的合成 方法. $\mathrm{Su}$ 等 ${ }^{[58]}$ 首先原位热解石墨烯/有机钴配合物, 得到 graphene/Co 络合物, 然后再使用 CVD 法在石墨烯基底 上生长碳纳米管. 这种 graphene/Co 络合物的制备是首 次被提到，因而他们的这种方法也为 CVD 法制备石墨 烯/碳纳米管复合材料开辟了一条新道路.

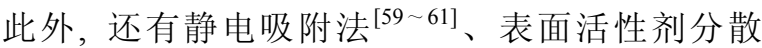
法 $^{[62]}$ 、电弧放电法 ${ }^{[63]}$ 、液一气界面杂化法 ${ }^{[64]}$ 、涂抹法 ${ }^{[65]}$ 、 刮刀成膜法 [66]等方法被用来制备石墨烯/碳纳米管复合 材料. 由于石墨烯/碳纳米管复合材料优越的电化学和 机械方面的性能，该复合材料在实际中的应用也越来越 广泛，将会有更多的简单实用的方法来制备石墨烯/碳 纳米管复合材料.

对于上述主要制备方法的优缺点进行了总结，详见 表 1 .

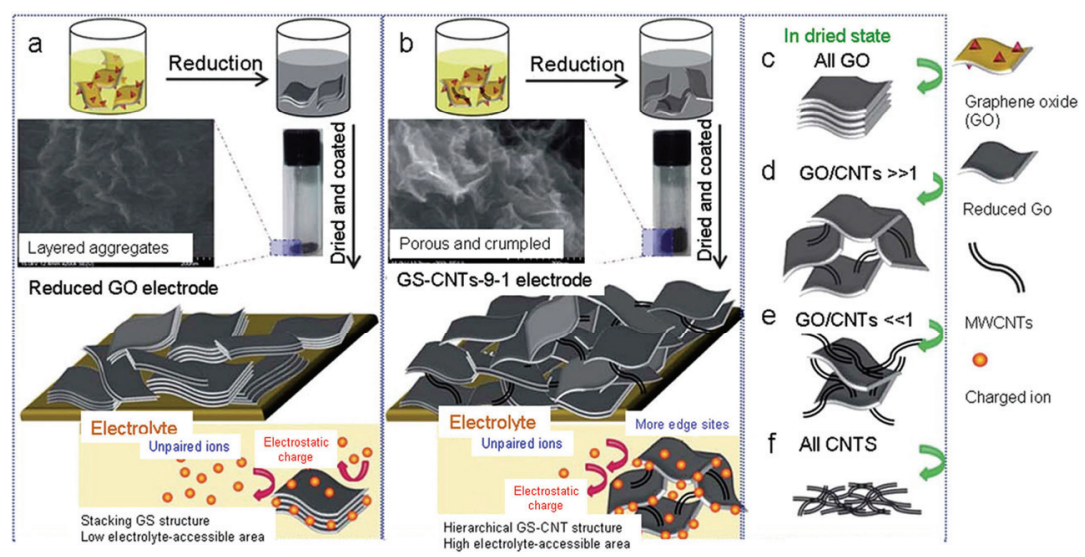

图 4 制备还原石墨烯电极(a)和 GS/CNTs-9-1 电极(b)的示意图 ${ }^{[55]},(\mathrm{c}),(\mathrm{d}),(\mathrm{e})$ 和(f)是注释

Figure 4 Scheme for preparing (a) reduced GO electrode and (b) GS/CNTs-9-1 electrode ${ }^{[55]}$. (c), (d), (e) and (f) are the notes 
表 1 石墨烯/碳纳米管复合材料制备方法的优缺点

Table 1 Advantages and disadvantages of graphene/carbon nanotube composite preparation methods

\begin{tabular}{|c|c|c|c|}
\hline \multicolumn{2}{|l|}{ 制备方法 } & \multirow{2}{*}{$\begin{array}{l}\text { 优点 } \\
\text { 能制备出均匀的薄膜, 而且薄膜的成分易于控制, 重 } \\
\text { 复性好, 不受基体表面形状的限制 }\end{array}$} & \multirow{2}{*}{$\begin{array}{l}\text { 缺点 } \\
C V D \text { 技术操作起来需要大于 } 800{ }^{\circ} \mathrm{C} \text { 的高温, 而有些器件 } \\
\text { 在高温环境下不稳定, 从而限制了常规 CVD 法在某些材 } \\
\text { 料制备上的应用 }\end{array}$} \\
\hline 化学气相沉 & 常规 CVD 法 & & \\
\hline 积(CVD)法 & $\begin{array}{l}\text { 等离子体增强 } \\
\text { CVD 法 }\end{array}$ & $\begin{array}{l}\text { 可以在较低的温度下进行化学气相沉积, 而且其沉积 } \\
\text { 速度快, 成膜质量好, 不易龟裂 }\end{array}$ & $\begin{array}{l}\text { 成本大, 对气体纯度要求高, 且在反应过程中会产生剧 } \\
\text { 烈噪音、强光辐射、有害气体等影响 }\end{array}$ \\
\hline \multicolumn{2}{|c|}{ 逐层沉积法(LBL) } & $\begin{array}{l}\text { 只需改变电解溶液的离子强度和 } \mathrm{pH} \text { 值, 就能改变组装 } \\
\text { 膜内吸附分子的链结构和组装膜的表面结构, 对组 } \\
\text { 膜的厚度、组分、密度进行调控. 与 CVD 法相比, LBL } \\
\text { 法制备石墨烯/碳纳米管复合薄膜方法简单、成本低、 } \\
\text { 应用范围广 }\end{array}$ & $\begin{array}{l}\text { 使用的原材料一般带有活性官能团, 例如羧基、氨基等, } \\
\text { 当用作电化学器件时, 在电流的催化下, 这些游离的官 } \\
\text { 能团易发生不可逆的氧化还原反应, 将会严重影响器件 } \\
\text { 的整体性能, 最终缩短其使用寿命 }\end{array}$ \\
\hline \multicolumn{2}{|l|}{ 电泳沉积法 } & $\begin{array}{l}\text { 沉积速率高、均质性好、膜厚易控且不需添加粘接剂, } \\
\text { 成本低等 }\end{array}$ & 对于基底的表面清洁度要求高 \\
\hline \multicolumn{2}{|l|}{ 真空抽滤法 } & $\begin{array}{l}\text { 该法制备的薄膜厚度可通过配置不同浓度和体积的悬 } \\
\text { 浮液得到精确的控制, 操作简单、成膜均匀以及原料 } \\
\text { 利用率高, 适合实验室条件下的基础科学研究 }\end{array}$ & $\begin{array}{l}\text { 成膜的面积受滤纸面积的限制, 而且在抽滤过程中, 由 } \\
\text { 于片层的层层叠加, 使得抽滤速度越来越慢直至停止, } \\
\text { 从而限制大厚度薄膜的制备 }\end{array}$ \\
\hline \multicolumn{2}{|l|}{ 涂制成膜法 } & $\begin{array}{l}\text { 相对于抽滤成膜技术, 该法制得薄膜的面积由衬底的 } \\
\text { 尺寸进行控制, 厚度可通过改变仪器的参数进行调节, } \\
\text { 制膜工艺简单高效 }\end{array}$ & $\begin{array}{l}\text { 该方法制得的薄膜厚度不均匀, 而且原料的利用率也相 } \\
\text { 对较低 }\end{array}$ \\
\hline \multicolumn{2}{|c|}{ 原位化学还原法 } & 方法简单, 制备速度快, 产量比较大 & 产品质量低, 氧化基团难以除净 \\
\hline
\end{tabular}

\section{3 石墨烯/碳纳米管和其它物质的掺杂改性}

由于石墨烯/碳纳米管复合材料的力学性能, 电容 性能和在结构上易于形成三维分级结构的特点, 人们往 往会向其中添加其它物质组成三元或多元复合材料, 用 来增强该复合材料的导电性、机械性、储能性等性能, 或 者使其具有某些特殊性能. 根据掺杂材料的不同, 得到 的性能也有所不同，而且选用的掺杂方法也不尽相同.

\section{1 与高分子材料的复合}

\section{1 .1 与导电高分子材料的复合}

导电高分子材料具有良好的导电性和电化学可逆 性, 可用作充电电池的电极材料. 导电高分子材料还是 制作超级电容器的理想材料, 如采用掺杂后的聚吡咯高 分子化合物, 电导率高达 $100 \mathrm{~S} / \mathrm{cm}$, 频率特征非常出色, 尤其在高频区的特性与以前电容器相比有很大改善. 但 是高分子在掺杂/脱掺杂过程中可能会发生膨胀和收缩, 降低了电容器的循环寿命. 石墨烯和碳纳米管具有高的 比表面积, 优异的电化学性能和机械性能被广泛应用在 制备超级电容器, 即将导电高分子复合到石墨烯/碳纳 米管中制备石墨烯/碳纳米管/高分子复合材料可应用于 制备更高性能的超级电容器. 近年来, 石墨烯/导电高分 子和碳纳米管/导电高分子二元复合材料被用来制备超 级电容器已有报道 ${ }^{[67 ~ 70]}$, 然而石墨烯/碳纳米管/导电高 分子三元复合材料在超级电容器中具有更好的电容量 和稳定的循环性, 这是因为二元复合材料中, 石墨烯的 力学增强性能优于碳纳米管, 但是石墨烯容易产生堆 叠, 而碳纳米管的导线导电性优于石墨烯, 三元复合材 料更易于形成三维分级结构, 又同时拥有了石墨烯和碳 纳米管的优点. 目前, 用来掺杂的导电高分子一般为聚

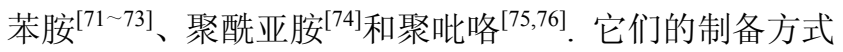

基本相同：首先通过原位聚合法制备碳纳米管/导电高 分子复合分散液, 然后再与石墨烯配制成三元混合溶 液, 随后真空过滤，即制成石墨烯/碳纳米管/导电高分 子三元复合薄膜.

$\mathrm{Lu}$ 等 ${ }^{[71]}$ 制备出碳纳米管/聚苯胺复合分散液后与氧 化石墨烯共分散, 真空过滤制备出复合薄膜, 然后再在 反应室内与肼蒸汽反应，使氧化石墨烯还原成石墨烯， 最后将该薄膜浸入含有过硫酸铵的盐酸溶液中, 即制得 均匀夹在石墨烯层中的同轴聚苯胺/碳纳米管复合材料 即石墨烯/碳纳米管/聚苯胺三元复合薄膜. 在另一个实 验中却是先使用氨水和肼溶液把氧化石墨烯还原成石 墨烯, 然后再与碳纳米管/聚吡咯复合溶液组成三元分 散液, 接着真空过滤制备出复合薄膜 ${ }^{[75]}$. 通过比较可发 现, 掺杂聚苯胺比掺杂聚吡咯所制得的电容器的单位电 容要大.

此外, 石墨烯/碳纳米管复合材料还可以替代聚二 氧乙基噻吩/聚苯乙烯磺酸(PEDOT/PSS $)^{[6,54,77]}$, 作为缓 冲层来修饰作为阳极的铟锡玻璃(ITO), 这是由于石墨 烯/碳纳米管的电荷收集/注入效果比 PEDOT:PSS 性能 好的多，而且石墨烯/碳纳米管复合材料更加均匀、透明 且稳定, 它可以修饰 ITO 电极, 使其表面更加光滑, 并 且提高电学性能的稳定性. 在制备光伏器件时, 选用聚 (3-己基噻吩) $/(6,6)$ 苯基 C61-丁酸甲酯为光敏单元功能层 材料, 石墨烯/碳纳米管复合薄膜对器件阳极进行修饰, 由此将大大提高光耦合器件的输出电流和电流传输率.

\section{1 .2 与非导电高分子材料的掺杂}

自从 1960 年起，高分子基质复合材料开始成为一 种全新的材料形式. 通过向高分子材料中添加分散性好 的、高强度的纤维，使得该复合材料的性能显著提高， 从而使其应用范围更加广泛. 由于碳材料大都具有良好 
的机械性能和热力学性能, 因而高分子与碳材料的复合 也逐渐被人们所关注. 人们一般是将碳纤维和碳纳米管 与高分子材料复合 ${ }^{[78 ~ 80]}$, 使得复合材料具有很好的导 电性、机械性能和热力学性能. 然而它们却有一定的缺 点 ${ }^{[81 \sim 83]}$, 例如碳纤维在聚合物中的分散性差、成本高等, 制约了碳纤维和碳纳米管与高分子材料的进一步发展 及应用. 自从石墨烯被发现以来, 由于其具有很大的长 径比和比表面积、高的导电性、独特的平面结构和较低 的制造成本, 因此, 石墨烯与高分子材料的复合也逐渐 引起了人们的关注 ${ }^{[84 ~ 90]}$. 但是由于石墨烯片层间大的 接触面积而引起大的范德华力, 导致石墨烯/高分子复 合材料极易聚集, 这种情况严重影响了该复合薄膜的物 理化学性质，限制了石墨烯和高分子材料的复合. 为了 解决这个问题，使用碳纳米管掺杂石墨烯与高分子材 料, 碳纳米管能够连接两片石墨烯并阻止其聚集, 因而 增大了石墨烯/碳纳米管与高分子材料的接触面积, 石 墨烯、碳纳米管、高分子三者间的协同效应使得该三元 复合材料具有卓越的机械性能和热力学性能. 其中环氧 树脂复合物研究的较多 ${ }^{[91 ~ 95], ~ Y a n g ~}$ 等 $^{[91]}$ 用环氧树脂作 为基体, 石墨烯为辅助增强材料制备复合材料, 石墨烯 有聚集问题, 将改性的碳纳米管添加到复合材料中, 长 径比大且弯曲的碳纳米管可以使两片石墨烯连接起来 并阻止了石墨烯的聚集, 从而增大了石墨烯/碳纳米管 与聚合物基体的连接面积且相容性好. 石墨烯/碳纳米 管的协同效应使得复合材料的机械性能和热力学性能 得到了极大的提高.

\section{2 与纳米粒子的掺杂}

当人们将宏观物体细分成超微颗粒(纳米级)后, 它 将显示出许多奇异的特性, 即它的光学、热学、电学、 磁学、力学以及化学方面的性质与大块物体相比有着显 著的不同. 因此, 石墨烯/碳纳米管复合材料与纳米粒子 的掺杂也逐渐获得了人们广泛的关注. Lee 等 ${ }^{[10]}$ 首先利 用 PECVD 法制备出石墨烯/碳纳米管复合薄膜, 随后用 $\mathrm{Au}, \mathrm{Ru}, \mathrm{Mn}$ 纳米颗粒修饰垂直生长的碳纳米管, 纳米金 属粒子可以调节碳纳米管的场致发射性质, 其中 $\mathrm{Mn}$ 纳 米粒子修饰的碳纳米管的场致发射性最好. Shen 等 ${ }^{[96]}$ 使 用液相法合成了三维 $\mathrm{TiO}_{2} / \mathrm{GNS} / \mathrm{CNT}$ 纳米复合材料, 制 备过程见图 5. 其中超细的 $\mathrm{TiO}_{2}$ 纳米晶体生长在二维石 墨烯和一维碳纳米管表面. 使用该复合材料修饰的电极 制备锂电池, 展现出快速高效的锂储存、高的可逆电容 和优秀的循环稳定性.

此外，还有人使用金纳米粒子修饰石墨烯/碳纳米 管复合材料用于生物检测 [97]、使用硅纳米粒子掺杂石墨 烯、碳纳米管组成三元复合材料制备超疏水性材料 $[26,98]$

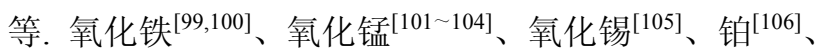

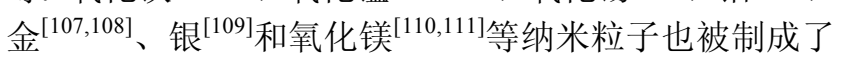
石墨烯、碳纳米管三元复合材料, 在电容器和催化等领 域得到了应用. 基于纳米粒子、石墨烯、碳纳米管它们

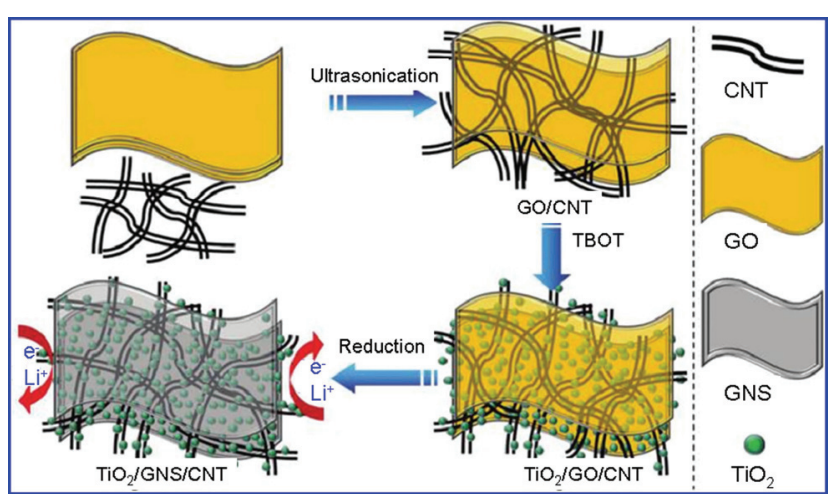

图 5 合成 $\mathrm{TiO}_{2} / \mathrm{GNS} / \mathrm{CNT}$ 三维纳米复合材料的示意图 ${ }^{[96]}$

Figure 5 Schematic illustration for the synthesis of 3D $\mathrm{TiO}_{2} / \mathrm{GNS} / \mathrm{CNT}$ nanocomposites ${ }^{[96]}$

各自特有的性质以及石墨烯和碳纳米管能够构成三维 网络的协同效应，相信在不久的将来，更多纳米粒子/石 墨烯/碳纳米管功能复合材料将会被人们所研究和应用.

\section{3 与其它材料的掺杂}

金属化合物一般为导电材料，因而与金属化合物的 掺杂可以提高石墨烯/碳纳米管的导电性. Huang 等 ${ }^{[112]}$ 使用掺杂碱金属碳酸盐的石墨烯/碳纳米管复合薄膜修 饰的电极, 可以有效地调节电极的功函数, 使电极与活 性层形成欧姆接触，因而增大了电荷的注入程度并改善 了光电设备的性能, 所以极大地推进了柔性、无 ITO 的 光电设备的发展.

金属氧化物可以用来修饰电容器的电极, 这是因为 电极表面的法拉第氧化还原反应使其储存能量，这种赝 电容性质可以使电容器表现出更高的单位电容. 但是金 属氧化物修饰的电极的导电性相对较低, 而且其循环周 期也是有限, 因此, 金属氧化物需要与其它材料掺杂改 性以提高超级电容器的电化学性能. Lei 等 ${ }^{[113]}$ 将 $\mathrm{MnO}_{2}$ 包覆的碳纳米管 $(\mathrm{MnC})$ 掺杂进石墨烯层中制备出可用于 超级电容器的 $\mathrm{MnO}_{2} / \mathrm{CNT}-\mathrm{RGO}$ 复合材料. 将碳纳米管 进行酸化处理，再与 $\mathrm{KMnO}_{4}$ 溶液直接氧化还原反应，使 $\mathrm{MnO}_{2}$ 包裹在碳纳米管表面(见图 6), 再与聚二甲基二烯 丙基氯化铵复合制得 PDDA- $\mathrm{MnO}_{2} / \mathrm{CNT}$ 复合材料，然后 与带有负电荷的石墨烯通过电泳沉积制备 $\mathrm{MnO}_{2}-$ $\mathrm{CNT} / \mathrm{RGO}$ 纳米复合材料. 经测试该复合材料的单位电 容是石墨烯/碳纳米管电容的 3 倍和二氧化锰/石墨烯复

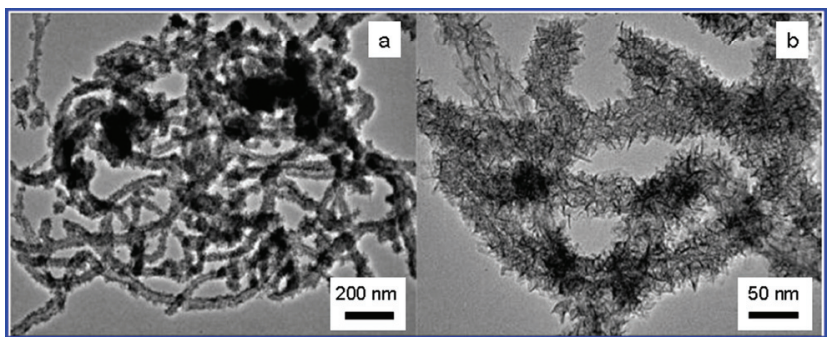

图 $6 \mathrm{MnC}$ 在低(a)和高(b)分辨率下的 TEM 照片 ${ }^{[113]}$

Figure 6 TEM images of MnC with (a) low and (b) high magnifications $^{[113]}$ 
合材料的 2 倍且稳定性很好.

此外, 金属阳离子也可以增强石墨烯/碳纳米管复 合材料的性能, 例如 Liu 等 ${ }^{[14]}$ 使用二价金属离子通过配 位化学键连接碳纳米管和化学修饰后的石墨烯来制备 $\mathrm{M}^{2+}$ /石墨烯/碳纳米管复合材料, 利用旋涂法制备出高 透明导电电极, 具有很高的弹性和强度. 由于金属化合 物在电学方面的特殊性能, 使得石墨烯/碳纳米管/金属 化合物三元复合材料在电化学方面例如超级电容器方 面得到广泛的应用. 金属氧化物的赝电容性质, 使得其 与石墨烯/碳纳米管掺杂得到的复合材料具有更大的比 电容和更高的循环稳定性.

除此之外, 石墨烯/碳纳米管还能与其它物质掺杂 改性来制备复合材料, 例如与电解质溶液掺杂用于染料 敏化太阳能电池 ${ }^{[115]}$, 以上所有的掺杂都是为了使石墨 烯/碳纳米管复合材料的性能得到增强或通过石墨烯和 碳纳米管构成三维网络的协同效应而提高掺杂物的某 些性能. 基于石墨烯/碳纳米管掺杂复合材料的卓越的 物理化学性能以及在实际应用中的不同需求, 不同性能 的掺杂复合材料将会被人们关注和研究, 因而使得石墨 烯/碳纳米管复合材料的实际应用更加广泛.

\section{4 石墨烯/碳纳米管复合材料的几种特殊结构}

\section{1 三维柱状结构}

以上所提的石墨烯/碳纳米管复合材料虽然已经具 有优良的电化学性质, 但该复合材料在电学方面仍有可 以发展的潜力, 这是由于碳纳米材料碳平面间具有极强 的共价键而在横向层与层之间的范德华力却相对较弱, 导致面外导电性受到限制, 从而影响碳材料整体的导电 能力. 由此可以设想, 如果使垂直排列的碳纳米管以完 美的共价键连接在两层平行的石墨烯层间, 即组成三维 柱状结构, 将会使该复合材料的电学性能和机械性能得 到巨大的提高. 理论研究 ${ }^{[16 ~ 118]}$ 已经证明该三维柱状结 构具有极强的导电性和机械性能, 巨正则 Monte Carlo (GCMC) 模拟(见图 7)证明该三维柱状结构在掺杂锂阳 离子后具有很好的储氢能力 ${ }^{[116]}$. Roy 等 ${ }^{[117]}$ 用理论证明 该三维柱状结构的导热性受最小柱间距(minimum interpillar distance)和碳纳米管柱的长度(CNT-pillar length)的 控制.

目前, 已经成功地使用 CVD 法制备出随机取向的 碳纳米管/石墨烯夹层结构 ${ }^{[17]}$. 尽管该纳米结构在实际 应用中有一定潜力, 而且已有较好的理论基础和实验经 验，但是制备三维柱状石墨烯/碳纳米管分层结构仍有 一定的困难. 最近, Du 等 ${ }^{[119]}$ 通过热解酞菁染料向热膨 胀高度有序热解石墨 (HOPG) 中插入生长垂直排列 (VACNT)的碳纳米管, 制备出可调的三维柱状石墨烯/ 碳纳米管纳米结构(见图 8). 除了在超级电容器方面的 应用, 三维柱状石墨烯/碳纳米管在制备蓄电池、燃料电 池、纳米多孔储氢材料和导热导电材料等方面也有很大
的前景.
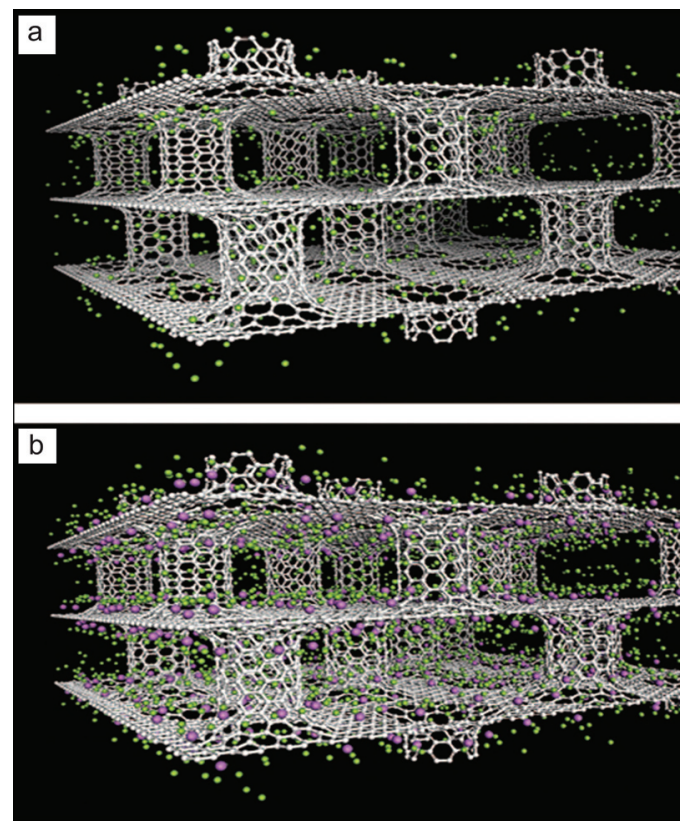

图 7 (a) GCMC 模拟纯柱状结构在 $77 \mathrm{~K}$ 和 $3 \mathrm{bar}$ 时的快照, 绿色的是 氢分子, (b) GCMC 模拟锂掺杂的柱状结构在 $77 \mathrm{~K}$ 和 3 bar 时的快照, 绿色的是氢分子, 紫色的是锂原子 ${ }^{[16]}$

Figure 7 (a) Snapshot from the GCMC simulations of pure pillared structure at $77 \mathrm{~K}$ and 3 bar. Hydrogen molecules are represented in green. (b) Snapshot from the GCMC simulations of lithium doped pillared structure at $77 \mathrm{~K}$ and 3 bar. Hydrogen molecules are represented again in green while lithium atoms are in purple ${ }^{[116]}$

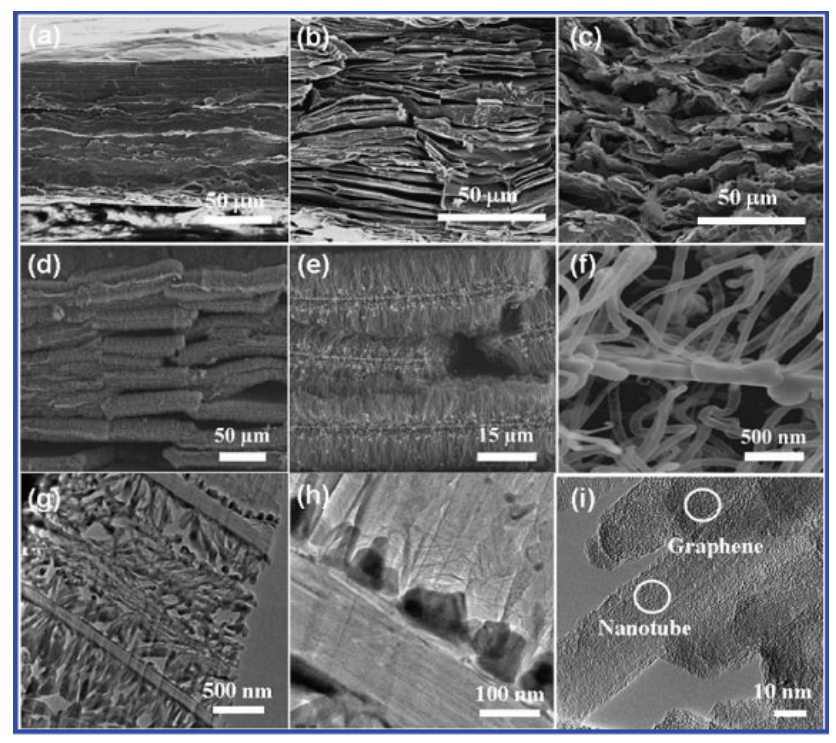

图 8 原 $\mathrm{HOPG}(\mathrm{a})$, 没有包覆 $\mathrm{SiO}_{2}$ (b)的酸处理热膨胀(b)和包覆 $\mathrm{SiO}_{2}$ (c)的扫描电镜照片, $(\mathrm{d} \sim \mathrm{f})$ 是典型的 $3 \mathrm{D}$ 柱状的 VACNT-石墨烯结构的 不同放大率下的 SEM 照片, $(\mathrm{g} \sim \mathrm{i})$ 是相应的是典型的 $3 \mathrm{D}$ 柱状的 VACNT-石墨烯结构的不同放大率下的 TEM 照片 ${ }^{[119]}$

Figure 8 SEM images of (a) the pristine HOPG and the acid-treated, thermally expanded HOPG (b) without and (c) with $\mathrm{SiO}_{2}$ coating. $(\mathrm{d} \sim \mathrm{f})$ Typical SEM images of the 3D pillared VACNT-graphene architectures under different magnifications. $(g \sim i)$ Cross-sectional TEM images of the 3D pillared VACNT-graphene architectures under different magnifications ${ }^{[119]}$ 


\section{2 石墨烯带螺旋插入或包裹碳纳米管}

当石墨烯的长径比足够大时, 可以自发地折叠成多 折结构或者螺旋结构 ${ }^{[120],} \mathrm{Li}$ 等 ${ }^{[121,122]}$ 通过分子动力学模 拟证明了石墨烯纳米带可以螺旋插入和包裹碳纳米管 形成螺旋结构, 这种结构已经非常接近在大自然中发现 的螺旋线, 衰减的势能表明该过程是自发进行的. 经过 分析可知, 石墨烯纳米带与碳纳米管间的范德华作用、 $\pi-\pi$ 共轭作用以及石墨烯开放边缘碳原子的悬浮的 $\sigma$-轨 道都对这种独特的现象产生影响. 两条石墨烯带可以形 成一种类似于 DNA 的双螺旋结构, 这种螺旋过程与碳 纳米管的直径和手性以及石墨烯的宽度有关. 此外, 他 们还提到了把石墨烯带的自发地包裹和插入现象应用 于药物供给以及制备新的纳米级功能设备的构想.

以上两种结构基本都还处在计算机模拟阶段，尽管 已有人初步实现了在纳米管中形成石墨烯带 ${ }^{[123]}$, 但离 真正的实现螺旋插入还有一定的距离. 此外, 还有几种 特殊的石墨烯/碳纳米管复合结构, 例如石墨烯片包裹

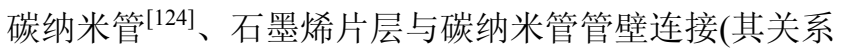
类似于树枝与树叶 $)^{[22,64]}$ 等, 特殊的结构也赋予了它们 特殊的性能, 而这些性能也是实际应用中所需要的, 因 此对于它们的研究将会不断地进行.

\section{5 石墨烯/碳纳米管复合材料的应用}

\section{1 在超级电容器中的应用}

超级电容器的储能密度、稳定性、可使用性等均取 决于电极材料的性能. 目前商业化的活性炭电极材料超 级电容器的比能量在 $0.2 \sim 20 \mathrm{Wh} / \mathrm{kg}$, 远低于镍氢电池 的 $60 \sim 80 \mathrm{Wh} / \mathrm{kg}$ 和锂离子电池的 $100 \sim 120 \mathrm{Wh} / \mathrm{kg}^{[125]}$, 主要是因为活性炭的比表面积的利用率较低. 因此, 从 石墨烯和碳纳米管出现以来, 由于其堆积材料潜在的大 比表面积而被广泛地应用于超级电容器 ${ }^{[126 ~ 129] . ~}$

基于石墨烯/碳纳米管复合材料的双电层电容 器 ${ }^{[8,17,33,53,55,130 ~ 133]}$ 已经有了大量的研究, 其中 $\mathrm{Lu}$ 等 ${ }^{[51]}$ 通过真空抽滤法制备的石墨烯/多壁碳纳米管复合薄膜 (多壁碳纳米管为 $16 \mathrm{wt} \%$ ) 比电容可达到 $265 \mathrm{~F} / \mathrm{g}$, 在 2000 次充放电循环后，比电容仅有 $3 \%$ 左右的损耗. $\mathrm{Yu}$ 等 ${ }^{[8]}$ 使用层层自组装制备的复合薄膜即使在高扫描速率 下仍有很高的比电容. Fan 等 ${ }^{[7]}$ 利用 CVD 法制备出三维 石墨烯/碳纳米管夹层结构, 这种结构具有很大的比表 面积, 而且能提供更多的电子运输通道因而导电性尤其 出色, 用该复合材料修饰的电极比电容可高达 $385 \mathrm{~F} / \mathrm{g}$. 另一种超级电容器为赝电容, 或者叫法拉第电化学电 容, 主要是利用活性材料的表面所进行氧化还原反应来 进行能量的存储, 活性材料主要采用过渡金属氧化物或 过渡金属氢氧化物例如氧化钻、氢氧化钻和氢氧化镍等. 这种法拉第电容的比电容值比基于碳材料的双电层电 容器更高, 但也正是由于还原反应的应用, 它的循环能
力大大降低, 经常在充放电几十次甚至几次后, 比电容 大大降低. 因而导致了使用碳材料与具有噟电容性材料 的复合材料作为超级电容器的电极修饰物, 这样不仅提 高了电容器的循环稳定性, 而且还增加了电极的单位电 容. $\mathrm{Du}$ 等 ${ }^{[119]}$ 在三维石墨烯/碳纳米管柱状结构表面生长 $\mathrm{Ni}(\mathrm{OH})_{2}$, 并使用这种复合材料作为超级电容器的电极, 单位电容大, 能量密度大且循环稳定性好. 在 $22.1 \mathrm{~A} / \mathrm{g}$ 时, 电容仍可达到 $1065 \mathrm{~F} / \mathrm{g}$ 左右, 同时还具有优异的循 环性.

利用碳纳米管和石墨烯这两种新型碳材料作为超 级电容器电极材料使得电容器的性能相较于传统电容 器更加优异, 在倡导无污染绿色能源的今天, 储能材料 扮演着极其重要的角色, 超级电容器作为一种新兴的储 能材料, 在进行了短短几十年的研究后, 展现出了不可 替代的作用，相信随着材料制备工艺的不断优化，材料 合成的控制更为准确, 在不久的将来, 超级电容器一定 会起到举足轻重的作用.

\section{2 在光电转换器件中的应用}

石墨烯/碳纳米管复合材料在光电转换器件中一般 被用来用做电极材料，尤其是用该复合材料制备的透明 导电电极, 在发光器件、太阳能电池等领域有着广泛的 应用。

\section{2 .1 在太阳能电池中的应用}

能源是世界经济发展的首要问题，当前，许多国家 都把发展新能源作为应对金融危机、加快经济复苏的重 要举措. 作为一种 “取之不尽、用之不竭” 的洁净的天 然能源, 太阳能成为最有希望的能源之一. 目前研究和 应用最广泛的太阳能电池主要是硅系太阳能电池，但硅 系电池原料成本高、生产工艺复杂、效率提高潜力有限, 其光电转换效率的理论极限值为 $30 \%$, 因此其民用化受 到技术性限制，急需开发低成本的太阳能电池.

染料敏化太阳能电池(DSSCs) 价格相对低廉，制作 工艺简单，拥有潜在的高光电转换效率，所以极有可能 取代传统硅系太阳能电池, 成为未来太阳能电池的主 导. 染料敏化太阳能电池通常包含一个半导体电极、染 料敏化剂、氧化还原电解质和一个对电极. 对电极作为 还原催化剂, 通常是在带有透明导电薄膜的玻璃上镀上 铂，因为铂具有良好的催化性质和导电性. 但是铂可以 在电解质溶液中溶解而引起杂质 $\left(\mathrm{PtI}_{4}\right.$ 和 $\left.\mathrm{H}_{2} \mathrm{PtI}_{6}\right)$, 而且铂 电极的成本太高, 因而需要一种低成本、高的电化学活 性和稳定性的对电极替代材料. 近年来, 由于碳材料具 有低的制造成本、良好的稳定性以及优良的催化活性等, 使得使用碳材料(石墨、炭黑、碳纤维、碳纳米管、石墨 烯)替代铂制备对电极逐渐引起了人们的关注 ${ }^{[134 \sim 141]}$. 由于石墨烯与碳纳米管间的协同效应，使用石墨烯/碳 纳米管复合材料制备对电极比单独使用其中一种材料 制备对电极得到的染料敏化太阳能电池性能更好. 此领 域的协同作用在于石墨烯提供的巨大的总表面积，碳纳 
米管的导电性起到了导线作用, 连接石墨烯片, 形成了 网络结构, 可增加电极表面微孔的数量, 有利于更好的 吸收太阳能, 另外增强了电流传导速率. Choi 等 ${ }^{[11]}$ 报道 一使用化学气象沉积法制备用于 DSSCs 的多壁碳纳米 管/石墨烯复合电极. 先在 $\mathrm{SiO}_{2} / \mathrm{Si}$ 表面沉积石墨烯, 再 在石墨烯表面沉积碳纳米管即制备石墨烯/多壁碳纳米 管复合薄膜, 其中该 DSSCs 的光电转换效率在 $4.46 \%$. Battumur 等 ${ }^{[66]}$ 使用一种简单的刮刀成膜法制备的复合 电极测得的光电转换效率也达到了 $4 \%$ 左右. $\mathrm{Zhu}$ 等 ${ }^{[34]}$ 使用了电泳沉积法制备复合电极, 他们的创新在于利用 微波辐射法还原石墨烯，这样不仅避免了使用有毒的还 原剂, 而且石墨烯的产量较大, 该复合电极的光电转换 效率很高, 可与传统的铂电极相謧美.

为了提高 DSSCs 的光电转换率, 除了改变电极材 料外, 还可通过改进电解质溶液来实现 ${ }^{[34,115,127,142 ~ 147]}$. DSSCs 的电解质一般为液相, 这就带来了诸多问题, 例 如电解质的渗漏、腐蚀电池、高温失稳以及制造过程中 带来的复杂性等, 这就限制了 DSSCs 在室外大面积的 使用. 因此, 最近几年许多科研人员致力于开发出一种 基于离子液的准固相电解质 ${ }^{[34,127]}$, 但是与传统的有机 溶剂电解质相比, 其光电转换率还不能达到实际需求. Ahmad 等 ${ }^{[15]}$ 将石墨烯、碳纳米管和石墨烯与单壁碳纳 米管混合物引入 PMII (1-methyl-3-propylimidazolium iodide)离子液中制备准固体电解质, 将准固体电解质加 载 $\mathrm{TiO}_{2}$ 工作电极和铂对电极之间即制得 DSSCs. 其中 石墨烯/碳纳米管复合的 DSSCs 的光电转换率最高, 可 能是因为碳材料的加入使得对电极与离子液间的电子 转移增强, 而且还可以作为电化学还原 $\mathrm{I}_{3}^{-}$的催化剂. 热 重分析发现此复合的电解质的热稳定性很高, 达到 300 ${ }^{\circ} \mathrm{C}$. 除此之外, 还有人将石墨烯/碳纳米管复合材料用于 高分子太阳能电池 ${ }^{[77]}$, 使其取代 PEDOT/PSS, 作为透明 阳极的修饰层, 使电子能很好地在孔洞中运输, 从而提 高了太阳能电池的光电转换效率.

\section{2 .2 在显示设备方面的应用}

目前, 高品质的显示器正在向大面积和多样化的方 向发展, 而且未来的显示器要求为柔性的, 就像纸张一 样可以随意卷曲, 这就要求透明导电电极必须具备良好 的柔韧性. 当前, 最为常见的透明电极材料是铟锡金属 氧化物 ITO, 这是因为 ITO 具有很好的透明性和导电性, 同时还能减少对人体有害的电子辐射、紫外线以及红外 线. 由于随着铟资源的减少使得铟变的越来越昂贵, 而 且 ITO 脆性很大使其完全不适宜于制备柔性设备, 因 此, 开发低能耗、高产率、易加工的新一代柔性透明导 电材料成为科学界和企业界竞相追逐的目标. 碳纳米管 与石墨烯的发现为制备透明导电电极开辟了一条新途 径, 这是由于石墨烯/碳纳米管复合薄膜在电荷迁移率、 透光性、化学稳定性、机械性能等方面具有优异的性能, 是柔性电极的理想材料. 影响透明导电电极性能的因素
主要有电阻率和透光比, 为了在不影响薄膜透明性的前 提下最大可能地增加其导电性, Jang 等 ${ }^{[53]}$ 对石墨烯/碳纳 米管复合薄膜进行了两次酸处理来提高氮原子密度，使 其形成化学 $\mathrm{p}$ 型掺杂的复合薄膜. 使用该薄膜修饰的玻 璃电极的表面电阻为 $171 \Omega / \mathrm{sq}$, 在波长为 $550 \mathrm{~nm}$ 时透过 率高达 $84 \%$. 为了不影响透明电极的柔性, 石墨烯/碳纳 米管复合薄膜的制备必须在较温和的环境下进行，一般 为低温液相过程 ${ }^{[30,77]}$. Liu 等 ${ }^{[114]}$ 通过向石墨烯/碳纳米管 中掺杂二价金属离子，从而使该薄膜具有极强的柔韧性 和透明性. 他们的这种方法也为制备强柔韧性的透明导 电电极开辟了一条新途径. 此外, Kim 等 ${ }^{[16]}$ 利用 PECVD 法制备出能在高温等恶劣环境下保持了其透明性和导 电性石墨烯/碳纳米管复合薄膜, $1 \mu \mathrm{m}$ 长, $2 \mu \mathrm{m}$ 宽的矩阵 点, $15 \mu \mathrm{m}$ 的管间距的垂直碳纳米管矩阵生长在石墨烯 基底上. 这种方法制备的透明导电的柔性光学元件或许 可以用于三维全息成像.

\section{3 在储能电池中的应用}

\subsection{1 在锂离子电池中的应用}

锂离子电池自从 1990 年被索尼公司商业化以来, 由于其具有稳定的循环性和高的能量密度，因而被广泛 地应用在手机、笔记本电脑、数码相机等领域. 随着时 代的进步和科技的发展，人们对储能设备的要求也越来 越高, 以石墨为电极的传统锂离子电池已经很难满足现 代设备的需求，因此急需找到一种高密度的电极材料来 代替石墨. 由于石墨烯和碳纳米管具有很大的比表面 积、良好的导电性和很好的机械性能, 因而被认为是最 有潜力的电极替代材料 ${ }^{[148,149]}$. Honma 的研究小组 ${ }^{[144]}$ 研 究了以石墨烯为电极的锂离子电池的性能, 由于化合物 层间的锂离子的协同作用受石墨烯片层之间距离的影 响, 通过添加碳纳米管、富勒烯等功能纳米碳材料来调 节石墨烯片层的距离以提高其比电容值. 但其石墨烯/ 碳纳米管复合材料只是通过简单的物理混合，因而它们 间的协同效应相对较弱, 而且其循环稳定性较差, 在 20 个充电/放电循环后，电容量仅为初始电容的 $66 \%$ 左右. 为了解决循环稳定性差的问题, Chen 等 ${ }^{[15]}$ 使用化学气相 还原沉积法制备出一种多层的石墨烯/碳纳米管复合阳 极材料，通过使得碳纳米管原位生长在石墨烯表面而解 决了石墨烯在复合材料中的分散和稳定性问题. 碳纳米 管的长度是影响电化学性能的主要因素, 短碳纳米管制 备出的复合电极具有更好的循环稳定性、更高的电容和 功率. 此外, 为了增加锂离子电池的安全性能, Shen 等 ${ }^{[96]}$ 往石墨烯/碳纳米管复合材料中添加 $\mathrm{TiO}_{2}$ 合成了一 种三维纳米复合材料, $\mathrm{TiO}_{2}$ 均匀地分散在石墨烯和碳纳 米管的表面而快速有效地存储和释放锂离子. 在锂离子 的嵌入/脱嵌过程中, $\mathrm{TiO}_{2}$ 具有很高的可逆容量和低的体 积膨胀, 极大地增强了电极的结构稳定性和使用寿命.

\section{3 .2 在燃料电池中的应用}

作为燃料电池的一种, 质子交换膜然料电池(Proton 
exchange membrane fuel cells, PEMFCs), 是其中最新型 的、有远大前途的燃料电池. 由于 PEMFCs 具有高的能 源效率、低的污染排放和工作温度低等优点, 因此被广 泛用在便携式电子设备、汽车内燃机中的电池替代品. 在 PEMFCs 中, 一般使用铂基电化学催化剂作为电极材 料, 一个最重要的商业化目标就是在不影响 PEMFCs 性 能的前提下尽可能的减少铂的用量. 为了使铂电极的催 化效率发挥至最大, 铂电极应该与气体、电子传导介质 和质子传导介质同时接触. 由于质子的扩散作用, 为了 尽可能地减少铂的损失, 因此催化层要尽可能薄. 目前, 很多碳材料被用来作为 PEMFCs 电极的催化剂载体, 这 种催化剂载体对于 PEMFCs 来说至关重要, 其中催化剂 颗粒的尺寸、分散程度、分布以及稳定性都与催化剂载 体息息相关. 与传统的碳材料相比, 使用纳米尺寸的碳 材料(石墨烯、碳纳米管等)作为催化剂的载体可以更有 效地减少铂的载入 ${ }^{[150 ~ 152]}$. 由于使用石墨烯/碳纳米管 复合材料比单独使用石墨烯或碳纳米管获得的效果更

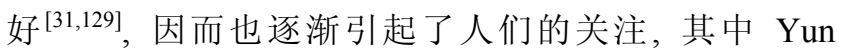
等 ${ }^{[147]}$ 制备了用于质子交换膜燃料电池的铂-石墨烯/碳 纳米管复合电极, 棒状的具有很大长径比的碳纳米管赋 予复合材料的多孔网络结构, 铂一石墨烯均匀分散在碳 纳米管的表面, 使得同时有利于铂的电催化和反应的进 行. 该复合材料电极的功率密度是铂-石墨烯电极功率 密度的四倍, 而铂的单位负载量却低于铂-石墨烯电极.

直接甲醇然料电池 (Direct Methanol Fuel Cell, DMFC) 属于质子交换膜然料电池(PEMFC)中之一类, 不 同之处是使用甲醇为燃料. 相较于 PEMFC, DMFC 具备 低温快速启动、燃料洁净环保以及电池结构简单等特性. 这使得 DMFC 可能成为未来便携式电子产品应用的主 流. 由于 DMFC 也是采用贵金属纳米催化剂(一般为 $\mathrm{Pt}$ 和 $\mathrm{Ru}$ )而极大地限制了它的进一步发展. Jha 等 ${ }^{[98]}$ 使用功 能化的石墨烯(f-G)和功能化的多壁碳纳米管(f-MWNT) 为催化剂基体材料, 将 $\mathrm{PtRu} / \mathrm{Pt}$ 纳米材料进行掺杂制备 复合材料用于直接甲醇燃料电池. $\mathrm{PtRu} / \mathrm{Pt}$ 纳米粒子和功 能化的石墨烯会组织石墨烯的堆积从而增大催化层的 表面积. 实验证明在直接甲醇燃料电池中甲醇的氧化反 应中 $\mathrm{PtRu} /(\mathrm{f}-\mathrm{G}-\mathrm{f}-\mathrm{MWNT})$ 复合纳米材料的电催化活性优 于 $\mathrm{PtRu} / \mathrm{f}-\mathrm{MWNT}$ 或者 PtRu/f-G. 使用石墨烯/碳纳米管 复合材料作为电极的催化剂载体, 不仅可以增强催化活 性、提高导电能力, 还可以有效地减少膜电极上铂的载 入量, 直接降低了燃料电池的生产成本, 这就为其商品 化的实现准备了条件.

\section{4 在电化学传感器中的应用}

电化学传感器是基于待测物的电化学性质并将待 测物化学量转变成电学量进行传感检测的一种设备, 它 的应用十分广泛, 例如环境监测、药品检测、食品安全、 医学等方面. 由于纳米材料的特殊性能, 因而被广泛的 用于修饰电化学传感器的玻璃碳电极(GCE), 碳纳米管
和石墨烯是其中最具有发展潜力的两种电极修饰材料, 可以使传感器更加敏捷、稳定 ${ }^{[153 \sim 158]}$.

\section{4 .1 化学传感器}

石墨烯/碳纳米管复合材料在化学传感器中有着重 要的应用 ${ }^{[57,65,159 ~ 164]}$. Chen 等 ${ }^{[65]}$ 使用石墨烯/单壁碳纳米 管复合薄膜修饰玻璃碳电极制备了用于检测 APAP 的电 化学传感器, 此电化学传感器呈现出优异的选择性和稳 定性. $\mathrm{Hu}$ 等 ${ }^{[57]}$ 还解决了几种污染水资源的酚类化合物 不容易区分检测的问题，由于石墨烯/碳纳米管复合材 料具有优异的催化活性、增强的导电性、高比表面积和 多孔结构使得通过使用石墨烯/多壁碳纳米管复合材料 修饰的电极对样品进行 CV 分析, 成功地同时区分检测 了样品中的对苯二酚、邻苯二酚、甲酚和亚硝酸盐.

\section{4 .2 生物传感器}

酶生物传感器由于其方法简单、灵敏度高、选择性 好等特点而越来越受到了人们的广泛关注并取得迅猛 的发展. 然而, 由于酶分子难于固定到电极表面, 酶本 身易失活且酶分子量大, 酶的活性中心深埋在多肽结构 内部, 很难发生直接电子传递, 因此如何有效的利用生 物分子固定技术及固定材料来保持酶的活性、提高酶的 固载量以及加速电子传递速率或直接研制新型的无酶 型传感器是制备性能优良的 $\mathrm{H}_{2} \mathrm{O}_{2}$ 传感器的关键问题和 当务之急. 由于石墨烯和碳纳米管具有极大的比表面积 和多孔洞结构，因此在提高酶的固载量方面有着显著的 效果 ${ }^{[165 ~ 168]}$. Sheng 等 ${ }^{[108]}$ 在石墨烯-碳纳米管-全氟磺酸/ 金-铂合金纳米颗粒(GE-CNT-Nafion/AuPt NPs)修饰电 极的表面沉积聚苯胺制备了基于 $\mathrm{H}_{2} \mathrm{O}_{2}$ 的生物传感器, 即通过吸附法与电化学聚合法结合来增加酶的载入量. 由于静电作用, 在聚苯胺的聚合过程中 HRP 很好的掺 杂在其中; 此外, 石墨烯、碳纳米管和纳米金属离子具 有极大的比面积和多孔结构因而吸附能力很强, 可以牢 固地吸附 HRP 等蛋白质生物分子, 而且合金纳米粒子 比单独一种金属纳米粒子具有更高的催化活性、催化选 择性以及能更好的阻止酶的失活. 该传感器对 $\mathrm{H}_{2} \mathrm{O}_{2}$ 的 检测呈现出快速、高灵敏性和极低的检测限等特点. 石 墨烯/碳纳米管复合材料在酶的固定方面有着极大的应 用前景, 相信在制备高灵敏、高稳定的生物酶传感器领 域，该复合材料将会得到更加广泛的应用.

对于免疫传感器来说, 电极的界面性质对其影响极 大，这是由于电极界面的结构、导电性、表面面积和生 物相容性对电子转移、传质以及信号转换起着决定性作 用, 因此电极材料的选择对免疫传感器的性能至关重 要. 石墨烯/碳纳米管复合材料具有很好的物理化学性 质和卓越的生物惰性, 使得它们在免疫传感器电极修饰 材料的应用中逐渐崭露头角.

$\mathrm{Lu}$ 等 ${ }^{[97]}$ 使用金纳米粒子掺杂的石墨烯/碳纳米管复 合材料修饰电极制备电化学免疫传感器检测人类血清 中的人线毛膜促性腺激素(human chorionic gonadotro- 
phin, hCG). 且利用硫堇 (TH) 作为媒介体, 介孔材料 MCM-41 作为载体, 使辣根过氧化物酶结合 hCG (HRP$\mathrm{Ab} 2)$ 后与 $\mathrm{Au} / \mathrm{TH} / \mathrm{MCM}-41$ 作用结合并以此结合物使免 疫传感器的灵敏度得到增强. 该电化学免疫生物传感器 的制备过程及工作原理如图 9 所示.

经过 $\mathrm{CV}$ 测试, 该电极对 $\mathrm{hCG}$ 的检出限为 0.0026 $\mathrm{mIU} \cdot \mathrm{mL}^{-1}$, 线性响应范围为 $0.005 \sim 500 \mathrm{mIU} \cdot \mathrm{mL}^{-1}$. 此 外, Liu 等 ${ }^{[167]}$ 采用层层组装制备了还原石墨烯/碳纳米管 复合电极制备生物免疫传感器并成功地检测了人类血 清中的免疫球蛋白 (IgG). 由于这种免疫传感器表现出 很高的精确度和很好的稳定性及重现性, 因此为今后其 它生物分子的临床免疫检测提供了一个新的平台.

\section{5 在其它方面的应用}

石墨烯/碳纳米管复合材料除了在光电器件、储能电 池以及电化学传感器中的广泛应用外, 在其它领域也有 着很好的应用前景, 例如 $\mathrm{Ai}$ 等 ${ }^{[169]}$ 制备的柱状石墨烯/碳 纳米管复合材料并将之用于染料的吸附剂, 经过吸附实 验测试，该复合材料对亚甲基蓝的最大吸附量可达 $81.97 \mathrm{mg} / \mathrm{g}$, 在亚甲基蓝的初始浓度为 $10 \mathrm{mg} \cdot \mathrm{L}^{-1}$ 时清除 效率达到 97\%, 因此这种复合材料可以用于清除水资源 中的有机染料污染. Sui 等 ${ }^{[170]}$ 通过加热氧化石墨烯和碳 纳米管与维他命 $\mathrm{C}$ 的混合物制备水凝胶前驱体, 通过超 临界 $\mathrm{CO}_{2}$ 干燥此水凝胶前驱体制备石墨烯/碳纳米管混 合气凝胶. 此石墨烯/碳纳米管混合气凝胶可以清除河 水中的有机染料、重金属离子等污染, 为治理水污染提 供了新方法. Kim 等 ${ }^{[26,171]}$ 将氧化石墨烯/碳纳米管复合 材料用于激光解吸电离飞行时间质谱(LDI-TOF-MS)的 辅助基质, 并将之用于小分子化合物分子量的测定. 除 此之外, 石墨烯/碳纳米管复合材料还有很多应用需要 我们去开发探索.

\section{6 结论}

石墨烯和碳纳米管具有非常优良的物理化学性质, 由于石墨烯和碳纳米管间的协同效应，使得石墨烯/碳 纳米管复合材料的导电性、机械性等性能得到增强, 近
十年来，石墨烯/碳纳米管复合材料的制备方法日趋成 熟, 在制备光电器件、储能电池、电化学传感器等领域 的应用也逐渐崭露头角, 但是仍面临着艰巨的挑战. 第 一，复合材料的主要制备方法都有各自的缺点和不足， 要想获得操作易控、生产成本低、原料利用率高、产品 质量优良的制备方法还需深入研究与探索. 第二, 在石 墨烯与碳纳米管之间形成特殊结构的复合材料的制备 方面还有欠缺，制备碳纳米管在石墨烯层间高取向分布 的三维柱状结构和石墨烯带螺旋插入或包裹碳纳米管 结构的复合材料的制备还停留在计算机理论模型当中, 制备的三维柱状石墨烯/碳纳米管纳米结构还未实现碳 纳米管在石墨烯层间的高取向分布; 初步实现了在纳米 管中形成石墨烯带, 但离真正的实现螺旋插入还有一定 距离. 第三，石墨烯/碳纳米管复合材料的协同作用机制 的研究还不够深入, 尤其是理论方面. 综上所述, 制备 方法的不断完善和协同机制的深入研究必将成为未来 发展重点，特殊结构尤其是有序结构制备和性能研究将 成为该材料研究的高端方向. 随着人们的研究热情的不 断提高以及越来越多的科研工作者投身到这一领域中 来，相信在不远的将来，石墨烯/碳纳米管复合材料的合 成方法将会更加多样化, 其应用除在能源和光电器件领 域深化外，还会向其它领域延伸.

\section{作者简介}

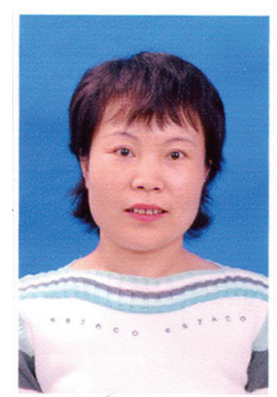

赵冬梅, 女, 满族, 博士，黑龙江东方学院副教授，硕士 生导师，东北林业大学在站博士后. 主要从事生物质纳米复合

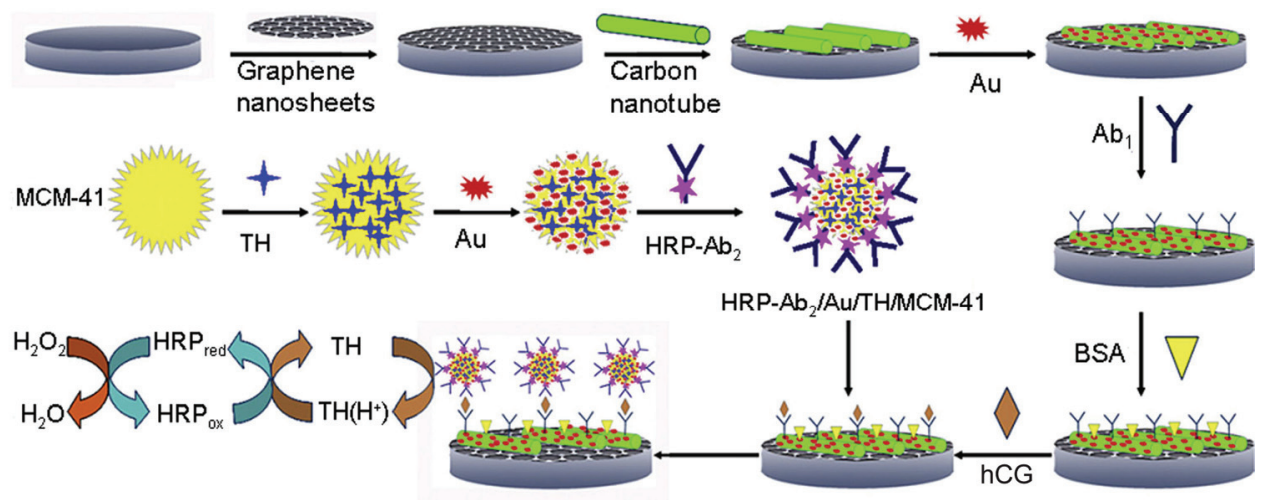

图 $9 \mathrm{Au} / \mathrm{TH} / \mathrm{MCM}-41$ 纳米材料的制备过程以及电化学免疫传感器的测量方法 ${ }^{[97]}$

Figure 9 Fabrication process of Au/TH/MCM-41 nanomaterials and measurement protocol of the electrochemical immunosensor ${ }^{[97]}$ 
材料的研究, 主持中国博士后基金资助项目 1 项和黑龙江省青 年骨干项目等 3 项, 发表论文 20 余篇, 获得授权专利 5 项, 出 版教材 2 部.

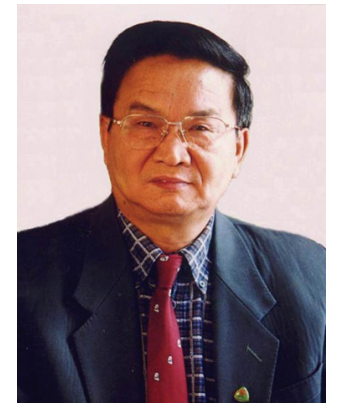

李坚, 男, 汉族, 东北林业大学教授, 博士生导师, 中国 工程院院士. 在国内生物木材学、生物质纳米复合材料等领域 率先开拓研究, 主持完成 “863” 等 10 余项国家、省部级重大 科研项目。获国家技术发明二等奖 1 项, 国家科技进步二等奖 1 项, 省科学技术一等奖 1 项, 省重大科技效益奖 1 项, 省部级 科技进步二等奖 4 项. 出版学术著作近 20 部, 发表论文 200 余篇.

\section{References}

[1] Rao, C. N. R.; Sood, A. K.; Subrahmanyam, K. S.; Govindaraj, A. Angew. Chem., Int. Ed. 2009, 48, 7752.

[2] Worsley, M. A.; Pauzauskie, P. J.; Olson, T. Y.; Biener, J.; Satcher, J. H., Jr.; Baumann, T. F. J. Am. Chem. Soc. 2010, 132, 14067.

[3] Guo, W. H.; Liu, C.; Sun, X. M.; Yang, Z. B.; Kia, H. G.; Peng, H. S. J. Mater. Chem. 2012, 22, 903.

[4] Varshney, V.; Patnaik, S. S.; Roy, A. K.; Froudakis, G.; Farmer, B. L. ACS Nano 2010, 4, 1153.

[5] Tung, V. C.; Chen, L. M.; Allen, M. J.; Wassei, J. K.; Nelson, K.; Kaner, R. B.; Yang, Y. Nano Lett. 2009, 9, 1949.

[6] Yoo, E.; Kim, J.; Hosono, E.; Zhou, H. S.; Kudo, T.; Honma, I.; Nano Lett. 2008, 8, 2277.

[7] Fan, Z. J.; Yan, J.; Zhi, L. J.; Zhang, Q.; Wei, T.; Feng, J.; Zhang, M. L.; Qian, W. Z.; Wei, F. Adv. Mater. 2010, 22, 3723

[8] Yu, D. S.; Dai, L. M. J. Phys. Chem. Lett. 2009, 1, 467.

[9] Peng, L. W.; Feng, Y. Y.; Lv, P.; Lei, D.; Shen, Y. T.; Li, Y.; Feng, W. J. Phys. Chem. C 2012, 116, 4970.

[10] Lee, D. H.; Lee, J. A.; Lee, W. J.; Choi, D. S.; Lee, W. J.; Kim, S. O. J. Phys. Chem. C 2010, 114, 21184.

[11] Choi, H.; Kim, H.; Hwang, S.; Kang, M.; Jung, D. W.; Jeon, M. Scripta Materialia 2011, 64, 601.

[12] Li, X.; Zhu, G. X.; Xu, Z. Thin Solid Films 2012, 520, 1959.

[13] Hong, S. W.; Du, F.; Lan, W.; Kim, S.; Kim, H. S.; Rogers, J. A. Adv. Mater. 2011, 23, 3821.

[14] Nguyen, D. D.; Tai, N. H.; Chen, S. Y.; Chueh, Y. L. Nanoscale 2012, 4, 632.

[15] Chen, S. Q.; Chen, P.; Wang, Y. Nanoscale 2011, 3, 4323.

[16] Kim, U. J.; Lee, I. H.; Bae, J. J.; Lee, S.; Han, G. H.; Chae, S. J.; Günes, F.; Choi, J. H.; Baik, C. W.; Kim, S. I.; Kim, J. M.; Lee, Y. H. Adv. Mater. 2011, 23, 3809.

[17] Li, C. Y.; Li, Z.; Zhu, H. W.; Wang, K. L.; Wei, J. Q.; Li, X.; Sun, P. Z.; Zhang, H.; Wu, D. H. J. Phys. Chem. C 2010, 114, 14008.

[18] Dong, X. C.; Li, B.; Wei, A.; Cao, X. H.; Chan-Park, M. B.; Zhang, H.; Li, L. J.; Huang, W.; Chen, P. Carbon 2011, 49, 2944.

[19] Zhu, X.; Ning, G. Q.; Fan, Z. J.; Gao, J. S.; Xu, C. M.; Qian, W. Z.; Wei, F. Carbon 2012, 50, 2764.

[20] Lee, D. H.; Kim, J. E.; Han, T. H.; Hwang, J. W.; Jeon, S.; Choi, S. Y.; Hong, S. H.; Lee, W. J.; Ruoff, R. S.; Kim, S. O. Adv. Mater. 2010, 22, 1247.

[21] Yu, K. H.; Lu, G. H.; Bo, Z.; Mao, S.; Chen, J. H. J. Phys. Chem. Lett. 2011, 2, 1556.

[22] Nagatsu, M.; Yoshida, T.; Mesko, M.; Ogino, A.; Matsuda, T.; Tanaka, T.; Tatsuoka, H.; Murakami, K. Carbon 2006, 44, 3336.

[23] Hong, T. K.; Lee, D. W.; Choi, H. J.; Shin, H. S.; Kim, B. S. ACS
Nano 2010, 4, 3861

[24] Byon, H. R.; Lee, S. W.; Chen, S.; Hammond, P. T.; Horn, Y. S. Carbon 2011, 49, 457.

[25] Hong, J.; Kang, S. W. Colloids Surf. A: Physicochem. Eng. Aspects 2011, 374, 54.

[26] Kim, Y. K.; Min, D. H. Langmuir 2009, 25, 11302.

[27] Lee, J.; Kim, Y. K.; Min, D. H. J. Am. Chem. Soc. 2010, 132, 14714.

[28] Su, Y.; Zhitomirsky, I. J. Colloid Interface Sci. 2013, 399, 46

[29] Wu, Z. S.; Pei, S. F.; Ren, W. C.; Tang, D. M.; Gao, T. L.; Liu, B.; Li, F.; Liu, C.; Cheng, H. M. Adv. Mater. 2009, 21, 1756.

[30] Bon, S. B.; Valentini, L. Kenny, J. M.; Peponi, L.; Verdejo, R.; Lopez-Manchado, M. A. Phys. Status Solidi A 2010, 207, 2461

[31] Lu, T.; Pan, L. K.; Li, H. B.; Nie, C. Y.; Zhu, M. F.; Sun, Z. J. Electroanal. Chem. 2011, 661, 270.

[32] Seo, S. D.; Hwang, I. S.; Lee, S. H.; Shim, H. W.; Kim, D. W. Ceram. Int. 2012, 38, 3017.

[33] Ata, M. S.; Sun, Y.; Li, X.; Zhitomirsky, I. Colloids Surf. A: Physicochem. Eng. Aspects 2012, 398, 9.

[34] Zhu, G.; Pan, L. K.; Lu, T.; Xu, T.; Sun, Z. J. Mater. Chem. 2011, $21,14869$.

[35] Eda, G.; Fanchini, G.; Chhowalla, M. Nat. Nanotechnol. 2008, 3, 270 .

[36] Wu, Z. C.; Chen, Z. H.; Du, X.; Logan, J. M.; Sippel, J.; Nikolou, M.; Kamaras, K.; Reynolds, J. R.; Tanner, D. B.; Hebard, A. F.; Rinzler, A. G. Science 2004, 305, 1273.

[37] Hu, L.; Hecht, D. S.; Gruner, G. Nano Lett. 2004, 4, 2513.

[38] Unalan, H. E.; Fanchini, G.; Kanwal, A.; Du Pasquier. A.; Chhowalla, M. Nano Lett. 2006, 6, 677.

[39] Kim, D. H.; Yun, Y. S.; Bak, H.; Cho, S. Y.; Jin, H. J. Curr. Appl. Phys. 2011, 11, 376.

[40] Khan, U.; O'Connor, I.; Gun'ko, Y. K.; Coleman, J. N. Carbon 2010, 48, 2825.

[41] Furtado, C. A.; Kim, U. J.; Gutierrez, H. R.; Pan, L.; Dickey, E. C.; Eklund, P. C. J. Am. Chem. Soc. 2004, 126, 6095.

[42] Giordani, S.; Bergin, S. D.; Nicolosi, V.; Lebedkin, S.; Kappes, M. M.; Blau, W. J.; Coleman, J. N. J. Phys. Chem. B 2006, 110, 15708.

[43] Landi, B. J.; Ruf, H. J.; Worman, J. J.; Raffaelle, R. P. J. Phys. Chem. B 2004, 108, 17089.

[44] Bergin, S. D.; Nicolosi, V.; Streich, P. V.; Giordani, S.; Sun, Z.; Windle, A. H.; Ryan, P.; Niraj, N. P. P.; Wang, Z. T. T.; Carpenter, L.; Blau, W. J.; Boland, J. J.; Hamilton, J. P.; Coleman, J. N. Adv. Mater. 2008, 20, 1876.

[45] Hernandez, Y.; Nicolosi, V.; Lotya, M.; Blighe, F. M.; Sun, Z. Y.; De, S.; Mcgovern, I. T.; Holland, B.; Byrne, M.; Gun'ko, Y. K.; Boland, J. J.; Niraj, P.; Duesberg, G.; Krishnamurthy, S.; Goodhue, R.; Hutchison, J.; Scardaci, V.; Ferrari, A. C.; Coleman, J. N. Nat. Nanotechnol. 2008, 3, 563.

[46] Tang, Y.; Gou, J. H. Mater. Lett. 2010, 64. 2513.

[47] King, P. J.; Khan, U.; Lotya, M.; De, S.; Coleman, J. N. ACS Nano 2010, 4, 4238

[48] Qiu, L.; Yang, X. W.; Gou, X. L.; Yang, W. R.; Ma, Z. F.; Wallace, G. G.; Li, D. Chem. Eur. J. 2010, 16, 10653.

[49] Zhang, C.; Ren, L. L.; Wang, X. Y.; Liu, T. X. J. Phys. Chem. C 2010, 114, 11435

[50] Tian, L. L.; Meziani, M. J.; Lu, F. S.; Kong, C. Y.; Cao, L.; Thorne, T. J.; Sun, Y. P. ACS Appl. Mater. Interfaces 2010, 2, 3217.

[51] Lu, X. J.; Dou, H.; Gao, B.; Yuan, C. Z.; Yang, S. D.; Hao, L.; Shen, L. F.; Zhang, X. G. Electrochim. Acta 2011, 56, 5115.

[52] Dong, X. C.; Xing, G. C.; Chan-Park, M. B.; Shi, W. H.; Xiao, N.; Wang, J.; Yan, Q. Y.; Sum, T. C.; Huang, W.; Chen, P. Carbon 2011, 49, 5071.

[53] Jang, W. S.; Chae, S. S.; Lee, S. J.; Song, K. M.; Baik, H. K. Carbon 2012, 50, 943 .

[54] Kim, J.; Tung, V. C.; Huang, J. X. Adv. Energy Mater. 2011, 1, 1052.

[55] Yang, S. Y.; Chang, K. H.; Tien, H. W.; Lee, Y. F.; Li, S. M.; Wang, Y. S.; Wang, J. Y.; Ma, C. C. M.; Hu, C. C. J. Mater. Chem. 2011, $21,2374$.

[56] Woo, S.; Kim, Y. R.; Chung, T. D.; Piao, Y. Z.; Kim, H Electrochim. Acta 2012, 59, 509.

[57] Hu, F. X.; Chen, S. H.; Wang, C. Y.; Ruo, Y. D. H.; Wang, C. Anal. Chim. Acta 2012, 724, 40.

[58] Su, Q.; Liang, Y. Y.; Feng, X. L.; Mullen, K. Chem. Commun. 2010, 46,8279 .

[59] Kim, Y. K.; Min, D. H. Langmuir 2009, 25, 11302. 
[60] Lee, J.; Kim,Y. K.; Min, D. H. J. Am. Chem. Soc. 2010, 132, 14714

[61] Vinayan, B. P.; Nagar, R.; Raman, V.; Rajalakshmi, N.; Dhathathreyan, K. S.; Ramaprabhu, S. J. Mater. Chem. 2012, 22, 9949.

[62] Tkalya, E. E.; Ghislandi, M.; With, G. D.; Koning, C. E. Curr. Opin. Colloid Interface Sci. 2012, 17, 225.

[63] Wu, Y. P.; Zhang, T. F.; Zhang, F.; Wang, Y.; Ma, Y. F.; Huang, Y.; Liu, Y. Y.; Chen, Y. S. Nano Energy 2012, 1, 820.

[64] Shao, J. J.; Lv, W.; Guo, Q. G.; Zhang, C.; Xu, Q.; Yang, Q. H. Kang, F.Y. Chem. Commun. 2012, 48, 3706.

[65] Chen, X.; Zhu, J. E.; Xi, Q.; Yang, W. S. Sens. Actuators, B 2012, 161,648 .

[66] Battumur, T.; Mujawar, S. H.; Truong, Q. T.; Ambade, S. B.; Lee, D. S.; Lee, W.; Han, S. H.; Lee, S. H. Curr. Appl. Phys. 2012, 12, 49.

[67] Liu, S.; Liu, X. H.; Li, Z. P.; Yang, S. R.; Wang, J. Q. New J. Chem. 2011, 35, 369 .

[68] Feng, X. M.; Li, R. M.; Ma, Y. W.; Chen, R. F.; Shi, N. E.; Fan, Q. L.; Huang, W. Adv. Funct. Mater. 2011, 21, 2989.

[69] Gupta, V.; Miura, N. Electrochim. Acta 2006, 52, 1721.

[70] Zhou, Y.; Qin, Z .Y.; Li, L.; Zhang, Y.; Wei, Y. L.; Wang, L. F.; Zhu, M. F. Electrochim. Acta 2010, 55, 3904

[71] Lu, X. J.; Dou, H.; Yang, S. D.; Hao, L.; Zhang, L. J.; Shen, L. F.; Zhang, F.; Zhang, X. G. Electrochim. Acta 2011, 56, 9224.

[72] Yan, J.; Wei, T.; Fan, Z. J.; Qian, W. Z.; Zhang, M. L.; Shen, X. D.; Wei, F. J. Power Sources 2010, 195, 3041.

[73] Ning, G. Q.; Li, T. Y.; Yan, J.; Xu, C. G.; Wei, T.; Fan, Z. J. Carbon 2013, 54, 241

[74] Zheng, Z. X.; Wang, Z. H.; Feng, Q. L.; Zhang, F. Y.; Du, Y. L.; Wang, C. M. Mater. Chem. Phys. 2013, 138, 350.

[75] Lu, X. J.; Dou, H.; Yuan, C. Z.; Yang, S. D.; Hao, L.; Zhang, F.; Shen, L. F.; Zhang, L. J.; Zhang, X. G. J. Power Sources 2012, 197, 319 .

[76] Ding, B.; Lu, X. J.; Yuan, C. Z.; Yang, S. D.; Han, Y. Q.; Zhang, X. G.; Che, Q. Electrochim. Acta 2012, 62, 132.

[77] Tung, V. C.; King, J.; Huang, J. X. Adv. Energy Mater. 2012, 2, 299.

[78] Saleh, M. H. A.; Sundararaj, U. Carbon 2009, 47, 2.

[79] Coleman, J. N.; Khan, U.; Blau, W. J.; Gun'ko, Y. K. Carbon 2006, 44, 1624.

[80] Qiu, L. B.; Sun, X. M.; Yang, Z. B.; Guo, W. H.; Peng, H. S. Acta Chim. Sinica 2012, 70, 1523. (丘龙斌, 孙雪梅, 仰志斌, 郭文瀚, 彭慧胜, 化学学报, 2012, 70, 1523.)

[81] Yang, D.; Hu, J. H.; Wang, C. C. Carbon 2006, 44, 3161.

[82] Yang, S. Y.; Ma, C. C. M.; Teng, C. C.; Huang, Y. W.; Liao, S. H.; Huang, Y. L.; Tien, H. W.; Lee, T. M.; Chiou, K. C. Carbon 2010, $48,592$.

[83] Zhang, Z. N.; Zhang, J.; Chen, P.; Zhang, B. Q.; He, J. S.; Hu, G. H. Carbon 2006, 44, 692.

[84] Ramanathan, T.; Abdala, A. A.; Stankovich, S.; Dikin, D. A.; Alonso, M. H.; Piner, R. D.; Adamson, D. H.; Schniepp, H. C.; Chen, X.; Ruoff, R. S.; Nguyen, S. T.; Aksay, I. A.; Prud'homme, R. K.; Brinson, L. C. Nat. Nanotechnol. 2008, 3, 327.

[85] Rafiee, M. A.; Rafiee, J.; Wang, Z.; Song, H. H.; Yu, Z. Z.; Koratkar, N. ACS Nano 2009, 3, 3884.

[86] Lu, W.; Lin, H. F.; Wu, D. J.; Chen, G. H. Polymer 2006, 47, 4440.

[87] Yu, A. P.; Ramesh, P.; Itkis, M. E.; Bekyarova, E.; Haddon, R. C. J. Phys. Chem. C 2007, 111, 7565.

[88] Li, J.; Sham, M. L.; Kim, J. K.; Marom, G. Compos. Sci. Technol. 2007, 67, 296

[89] Dai, J.; Lang, M. D. Acta Chim. Sinica 2012, 70, 1237. (戴静, 郎美 东, 化学学报, 2013, 70, 1237.)

[90] Zhang, S. P. Acta Chim. Sinica 2012, 70, 1394. (张树鹏, 化学学报, 2012, 70, 1394.)

[91] Yang, S. Y.; Lin, W. N.; Huang, Y. L.; Tien, H. W.; Wang, J. Y.; Ma, C. C. M.; Li, S. M.; Wang, Y. S. Carbon 2011, 49, 793.

[92] Im, H.; Kim, J. Carbon 2012, 50, 5429.

[93] Martin-Gallego, M.; Bernal, M. M.; Hernandez, M.; Verdejo, R.; Lopez-Manchado, M. A. Eur. Polym. J. 2013, 49, 1347.

[94] Starkova, O.; Chandrasekaran, S.; Prado, L. A. S. A.; Tölle, F.; Mülhaupt, R.; Schulte, K. Polym. Degrad. Stab. 2013, 98, 519.

[95] Li, W. K.; Dichiara, A.; Bai, J. B. Compos. Sci. Technol. 2013, 74, 221.

[96] Shen, L. F.; Zhang, X. G.; Li, H. S.; Yuan, C. Z.; Cao, G. Z. J. Phys. Chem. Lett. 2011, 2, 3096.

[97] Lu, J. J.; Liu, S. Q.; Ge, S. G.; Yan, M.; Yu, J. H; Hu, X. T. Biosens. Bioelectron. 2012, 33. 29.
[98] Jha, N.; Jafri, R. I.; Rajalakshmi, N.; Ramaprabhu, S. Int. J. Hydrogen Energy 2011, 36, 7284

[99] Chen, S. Q.; Bao, P.; Wang, G.X. Nano Energy 2013, 2, 425.

[100] Dervishi, E.; Biris, A. R.; Driver, J. A.; Watanabe, F.; Bourdo, S.; Biris, A. S. J. Catal. 2013, 299, 307.

[101] Deng, L. J.; Hao, Z. p.; Wang, J. F.; Zhu, G.; Kang, L. P.; Liu, Z. H.; Yang, Z. P.; Wang, Z. L. Electrochim. Acta 2013, 89, 191.

[102] Chen, Y.; Zhang, Y.; Geng, D. S.; Li, R. Y.; Hong, H. L.; Chen, J. Z.; Sun, X. L. Carbon 2011, 49, 4434.

[103] Kosynkin, D. V.; Higginbotham, A. L.; Sinitskii, A.; Lomeda, J. R.; Dimiev, A.; Price, B. K.; Tour, J. M. Nature 2009, 458, 872.

[104] Xia, H.; Lai, M. O.; Lu, L. J. Mater. Chem. 2010, $20,6896$.

[105] Chen, T. Q.; Pan, L. K.; Liu, X.J.; Yu, K. Sun, Z. RSC Adv. 2012, 2 , 11719.

[106] Zheng, Z. X.; Du, Y. L.; Wang, Z. H.; Zhang, F. Y.; Wang, C. M. J. Mol. Catal. A: Chem. 2012, 363 364, 481.

[107] Lu, J. J.; Liu, S. Q.; Ge, S. G.; Yan, M.; Yu, J. H.; Hu, X. T. Biosens. Bioelectron. 2012, 33, 29.

[108] Sheng, Q. L.; Wang, M. Z.; Zheng, J. B. Sens. Actuators, B 2011 , 160, 1070.

[109] Lian, W. J.; Liu, S.; Yu, J. H.; Li, J.; Cui, M.; Xu, W.; Huang, J. D. Biosens. Bioelectron. 2013, 44, 70.

[110] Li, S. M.; Wang, Y. S.; Yang, S. Y.; Liu, C. H.; Chang, K. H.; Tien, H. W.; Wen, N. T.; Ma, C. C. M.; Hu, C. C. J. Power Sources 2013, $225,347$.

[111] Zhu, X.; Ning, G. Q.; Fan, Z. J.; Gao, J. S.; Xu, C. M.; Qian, W. Z.; Wei, F. Carbon 2012, 50, 2764.

[112] Huang, J. H.; Fang, J. H.; Liu, C. C.; Chu, C. W. ACS Nano 2011, 5, 6262 .

[113] Lei, Z. B.; Shi, F. H.; Lu, L. ACS Appl. Mater. Interfaces 2012, 4, 1058

[114] Liu, Y. T.; Feng, Q. P.; Xie, X. M.; Ye, X. Y. Carbon 2011, 49, 3371

[115] Ahmad, I.; Khan, U.; Gun'ko, Y. K. J. Mater. Chem. 2011, 21, 16990.

[116] Dimitrakakis, G. K.; Tylianakis, E.; Froudakis, G. E. Nano Lett. 2008, 8,3166

[117] Varshney, V.; Patnaik, S. S.; Roy, A. K.; Froudakis, G.; Farmer, B. L. ACS Nano 2010, 4, 1153.

[118] Novaes, F. D.; Rurali, R.; Ordejon, P. ACS Nano 2010, 4, 7596.

[119] Du, F.; Yu, D. S.; Dai, L. M.; Ganguli, S.; Varshney, V.; Roy, A. K. Chem. Mater. 2011, 23, 4810.

[120] Lu, Q.; Huang, R. Mater. Res. Soc. Symp. Proc. 2011, 1284, 226.

[121] Jiang, Y. Y.; Li, H.; Li, Y. F.; Yu, H. Q.; Liew, K. M.; He, Y. Z.; Liu, X. F. ACS Nano 2011, 5, 2126.

[122] Li, Y. F.; Sun, F. W.; Li, H. J. Phys. Chem. C 2011, 115, 18459.

[123] Fujihara, M.; Miyata, Y.; Kitaura, R.; Nishimura, Y.; Camacho, C.; Irle, S.; Iizumi, Y.; Okazaki, T.; Shinohara, H. J. Phys. Chem. C 2012, 116, 15141 .

[124] Aravind, S. S. J.; Eswaraiah, V.; Ramaprabhu, S. J. Mater. Chem. 2011, 21, 15179 .

[125] Qu, D. Y.; Shi, H. J. Power Sources 1998, 74, 99.

[126] Najafabadi, A. I.; Yasuda, S.; Kobashi, K.; Yamada, T.; Futaba, D. N.; Hatori, H.; Yumura, M.; Iijima, S.; Hata, K. Adv. Mater. 2010, $22,235$.

[127] Futaba, D. N.; Hata, K.; Yamada, T.; Hiraoka, T.; Hayamizu, Y.; Kakudate, Y.; Tanaike, O.; Hatori, H.; Yumura, M.; Jima, S. I. Nat. Mater. 2006, 5, 987.

[128] Wang, H. L.; Casalongue, H. S.; Liang, Y. Y.; Dai, H. J. J. Am. Chem. Soc. 2010, 132, 7472.

[129] Wu, Z. S.; Wang, D. W.; Ren, W. C.; Zhao, J. P.; Zhou, G. M.; Li, F.; Cheng, H. M. Adv. Funct. Mater. 2010, 20, 3595.

[130] Zhang, L. L.; Xiong, Z. G.; Zhao, X. S. J. Power Sources 2013, 222 326.

[131] Buglione, L.; Pumera, M. Electrochem. Commun. 2012, 17, 45.

[132] Beidaghi, M.; Wang, C. L. Adv. Funct. Mater. 2012, 22, 4501.

[133] Zhang, D. S.; Yan, T. T.; Shi, L. Y.; Peng, Z.; Wen, X. R.; Zhang, J. P. J. Mater. Chem. 2012, 22, 14696.

[134] Veerappan, G.; Bojan, K.; Rhee, S. W. ACS Appl. Mater. Interfaces 2011, 3, 857.

[135] Lee, K. S.; Lee, W. J.; Park, N. J.; Kim, S. O.; Park, J. H. Chem. Commun. 2011, 47, 4264

[136] Guo, C. X.; Guai, G. H.; Li, C. M. Adv. Energy Mater. 2011, 1, 448.

[137] Kavan, L.; Yum, J. H.; Gratzel, M. ACS Nano 2011, 5, 165.

[138] Kavan, L.; Yum, J. H.; Gratzel, M. Nano Lett. 2011, 11, 5501.

[139] Tsai, T. H.; Chiou, S. C.; Chen, S. M. Int. J. Electrochem. Sci. 2011, 
$6,3333$.

[140] Kim, H.; Choi, H.; Hwang, S.; Kim, Y.; Jeon, M. Nanoscale Res. Lett. 2012, 7, 53.

[141] Hu, Y. H.; Wang, H.; Hu, B. ChemSusChem 2010, 3, 782.

[142] Stergiopoulos, T.; Rozi, E.; Hahn, R.; Schmuki, P.; Falaras, P. Adv. Energy Mater. 2011, 1, 569.

[143] Freitas, J. N. D.; Nogueira, A. F.; Paoli, M. A. D. J. Mater. Chem. 2009, 19, 5279 .

[144] Yoo, E.; Kim, J.; Hosono, E.; Zhou, H. S.; Kudo, T.; Honma, I. Nano Lett. 2008, 8, 2277.

[145] Lv, R. T.; Cui, T. X.; Jun, M. S.; Zhang, Q.; Cao, A. Y.; Su, D. S.; Zhang, Z. J.; Yoon, S. H.; Miyawaki, J.; Mochida, I.; Kang, F. Y. Adv. Funct. Mater. 2011, 21, 999.

[146] Yang, S. D.; Shen, C. M.; Lu, X. J.; Tong, H.; Zhu, J. J.; Zhang, X. G. Electrochim. Acta 2012, 62, 242.

[147] Yun, Y. S.; Kim, D.; Tak, Y.; Jin, H. J. Synth. Met. 2011, 161, 2460.

[148] Sun, H. M.; Cao, L. Y.; Lu, L. H. Acta Chim. Sinica 2013, 71, 579. (孙红梅, 曹林园, 逯乐慧, 化学学报, 2013, 71, 579.)

[149] Shi, G. Y.; Wang, Z. H.; Xia, J. F.; Zhang, F. F; Xia, Y. Z.; Li, Y. H. Acta Chim. Sinica 2013, 71, 227. (史国玉, 王宗花, 夏建飞, 张菲 菲, 夏延致, 李延辉, 化学学报, 2013, 71, 227.)

[150] Zou, Q.; Liu, J.; Zhu, G. B.; Zhang, X. H.; Chen, J. H. Acta Chim. Sinica 2013, 71, 1154. (邹琼, 刘娟, 朱刚兵, 张小华, 陈金华, 化 学学报, 2013, 71, 1154.)

[151] Tian, L. L.; Wei, X. Y.; Zhuang, Q. C.; Zong, Z. M.; Sun, S. G. Acta Chim. Sinica 2013, 71, 1270. (田雷雷, 魏贤勇, 庄全超, 宗志敏, 孙世刚, 化学学报, 2013, 71, 1270.)

[152] Chen, L.; Shen, L. F.; Nie, P.; Su, X. F.; Zhang, X. G.; Li, H. S. Acta Chim. Sinica 2012, 70, 15. (陈琳，申来法，聂平，苏晓飞, 张校刚, 李洪森, 化学学报, 2012, 70, 15.)

[153] Huang, K. J.; Niu, D. J.; Sun, J. Y.; Han, C. H.; Wu, Z. W.; Li, Y. L.; Xiong, X. Q. Colloids Surf. B: Biointerfaces 2011, 82, 543.

[154] Hu, C. G.; Hu, S. S. J. Sensors 2009, 2009, 1.
[155] Hernandez, F. J.; Ozalp, V. C. Biosensors 2012, $2,1$.

[156] Shao, Y. Y.; Wang, J.; Wu, H.; Liu, J.; Aksay, I. A.; Lin, Y. H. Electroanalysis 2010, 22, 1027.

[157] Kang, X. H.; Wang, J.; Wu, H.; Liu, J.; Aksay, I. A.; Lin, Y. H. Talanta 2010, $81,754$.

[158] Ahammad, A. J. S.; Lee, J. J.; Rahman, M. A. Sensors 2009, 9, 2289.

[159] Sablok, K.; Bhalla, V.; Sharma, P.; Kausha, R.; Chaudhary, S.; Suri, C. R. J. Hazard. Mater. 2013, 248 249, 322.

[160] Wang, X. L.; Li, L.; Wang, Y. P.; Xu, C. Z.; Zhao, B.; Yang, X. D. Food Chem. 2013, 138, 2195.

[161] Unnikrishnan, B.; Mani, V.; Chen, S. M. Sens. Actuators, B 2012 $173,274$.

[162] Arvand, M.; Gholizadeh, T. M. Colloids Surf. B: Biointerfaces 2013, $103,84$.

[163] Mani, V.; Devadas, B.; Chen, S. M. Biosens. Bioelectron. 2013, 41, 309.

[164] Shi, C. Y.; Meng, J. R.; Deng, C. H. J. Mater. Chem. 2012, 22, 20778.

[165] Chang, J. B.; Mao, S.; Zhang, Y.; Cui, S. M.; Steeber, D. A.; Chen, J. H. Biosens. Bioelectron. 2013, 42, 186.

[166] Lin, J. H.; Wei, Z. J.; Zhang, H. H. Shao, M. J. Biosens. Bioelectron. 2013, 41, 342 .

[167] Liu, Y.; Liu, Y.; Feng, H. B.; Wu, Y. M.; Joshi, L.; Zeng, X. Q.; Li, J. H. Biosens. Bioelectron. 2012, 35, 63.

[168] Chen, H. J.; Zhang, Z. H.; Xie, D.; Cai, R.; Chen, X.; Liu, Y. N.; Yao, S. Z. Electroanalysis 2012, 24, 2109

[169] Ai, L. H.; Jiang, J. Chem. Eng, J. 2012, 192, 156

[170] Sui, Z. Y.; Meng, Q. H.; Zhang, X. T.; Ma, R.; Cao, B. J. Mater. Chem. 2012, 22, 8767.

[171] Kim, Y. K.; Min, D. H. ACS Appl. Mater. Interfaces 2012, 4, 2088.

(Cheng, F.) 